\title{
BETWEEN ATTENTION AND MOBILISATION: PROLETARIAT POLITICAL ACTIVATION IN A MEDIATED AOTEAROA/NEW ZEALAND
}

BY

DANI PICKERING

\author{
A thesis \\ submitted to the Victoria University of Wellington \\ in fulfilment of the requirements for the degree of \\ Master of Arts \\ in Media Studies
}

Victoria University of Wellington

2019 


\begin{abstract}
Stagnant pay, increased work hours and other increasingly precarious working conditions are restricting the capacity of the working class to meaningfully participate in political processes, worsening its economic disenfranchisement and further widening the inequality gap. At the same time, political struggles have expanded beyond the economic. "New Social Movements" have for the last half century transformed politics by expanding the definition of "political struggle" to include environmental, cultural and social concerns. Information and communication technologies have also advanced considerably, to the extent that information and its transmission are no longer scarce. Instead, in an "attention economy" that operates under capitalist logics, it is the human capacity to process information that has the most limited availability. Together, these developments have fundamentally changed the ways in which people participate in politics today, with no clear consensus regarding the overall merit of these emergent means of participation for the class-based social movements looking to reverse growing economic inequality.
\end{abstract}

In this thesis, I examine the role of media in class-based social movements today. Specifically, I ask how organisers for these movements use media to facilitate political activation, or the process by which individuals disengaged from political processes come to participate in them. Using interviews with organisers from social movement organisations seeking to activate workingclass audiences, I conduct a thematic analysis of those organisations' media use and communications strategies. The findings reveal a complex imbrication of mediated and nonmediated activities designed to enable successful navigation of the attention economy. Through these findings, I propose new ways of connecting the individual to the collective in class-based movements through media. 


\section{Acknowledgments}

Jodi Dean asserts at the beginning of Crowds and Party that "writing is solitary. Thinking is collective" $(x)$. True to that adage, this thesis may be the product of my writing, but it is also the intellectual effort of a collective to better understand what we mean by and how we build "collectives". Of the people in that collective, I must first acknowledge Zak. Without your endless love, support, patience for me and impatience for the world of politics, I would never have finished this thesis. To my late grandmother, Christine: you played a vital role in facilitating my own political activation, regardless of how different our positions ended up being. That my activation mattered more to you than agreeing with me means the world. To the rest of my whānau, especially Andrew, Jodi and Jessica: though you supported me from afar for the majority of this endeavour, your support was essential nonetheless. To Kate, Huriana, Ti, Justine, Emmy, Kiran, Camellia, Sophie M., Aaliyah, Erica, Viveka, Rei-Marata, Jack, Hugo, Ben, Dan, Ricardo, Kassie and a frankly exhaustive list of every other comrade I have ever had a political kōrero with, organised with or fought alongside: this thesis was written for you. I dearly hope the work that we have done together helps you change the lives of everyone you reach. You've certainly changed mine. To Kathleen Kuehn: your ridiculously high expectations for the intellectual rigour of my work were invaluable. I am literally a smarter person now because of you. To Michael Daubs: you inspired me to pursue social movements academically even as I sought to contribute to building them directly. Your impact in this regard is greater now than you might think. To my SEFTMS postgraduate colleagues: dissertations are consistently isolating projects. Thank you for ensuring that at the very least, we could be alone together. Finally, I want to thank everyone who participated in the social movements taking place as I wrote this thesis (especially the \#SchoolStrike4Climate and the movement to \#Protectlhumātao) for demonstrating the importance of this research to the current political moment.

Ngā mihinui me arohanui ki a koutou katoa. 


\section{Contents}

Abstract.




\section{List of figures}

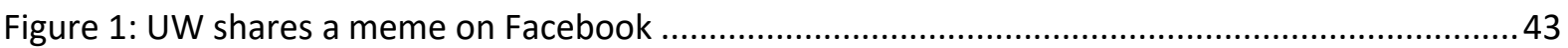

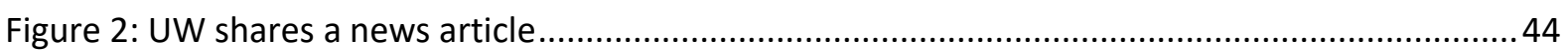

Figure 3: Example of PAPA's 'reckons' on Facebook .............................................................. 48

Figure 4: Example of PAPA's 'reckons' on Twitter ................................................................ 48

Figure 5: AAAP sharing a Scoop media release through its Facebook page......................................58

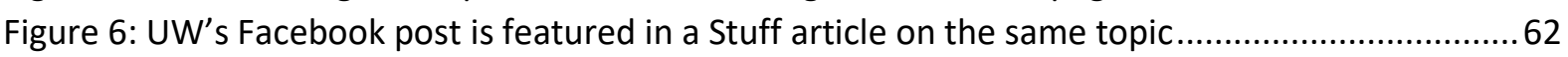

Figure 7: A diagram modelling a political activation process for social movements.........................89 


\section{Introduction}

The history of social movements is overwhelmingly defined by class struggle. Movements for control of a society's resources have catalysed some of the most significant societal transitions in recorded history. From the earliest ever recorded workers' strike in ancient Egypt (Steven, 2007), to the transition from feudalism to capitalism (Marx, 1867/2013), to the more recent Occupy movement with its "we are the 99\%" slogan, the social movements driving these transitions have been built on a collective identity that hinges on how that identity relates to those in control of society's material resources-in other words, on class.

Developments in the last half-century complicate this history. Globalised society is advancing to the extent that political struggles are expanding beyond the material considerations of food, wood and stone to include the institutions, cultures, and other components of society which have been produced through those materials. Instead of simply struggling for control of those materials, social movements like the American Civil Rights Movement, the feminist movement and the Māori renaissance have sought gains in struggles over human rights, cultural sovereignty, and other "postmaterial" political arenas (Inglehart, 1981). However, even the evolution of these struggles continues to draw on a collective - if not necessarily classed - character by continuing to speak to a struggle for "freedom against alienation" (Blackledge, 2013, p. 267) which acknowledges that material conditions are "neither the exclusive nor the basic focus of the experience of deprivation" (Habermas, 1981, as cited in Offe, 1985, p. 845). These "New Social Movements" (NSMs) have evolved out of opposition to the institutions, states and other ideological structures that control society and which, in broad terms, alienate and deprive their constituents. In the decades since their emergence, NSMs have produced social movement organisations (SMOs) of their own which are "unaligned with major political parties or trade unions" but, in doing so, have nonetheless "become a permanent component of Western democracies" (della Porta \& Diani 2006, p. 1). 
The other key development in social movements of recent decades has been in the technologies deployed by them. Developments in information and communication technologies (ICTs) have transformed how social movements organise and operate by making information and communications more accessible to the masses than ever before. Through strategic use of social media platforms like Facebook and Twitter, protests numbering from the hundreds to the hundreds of thousands can be mobilised overnight. Counterhegemonic messages that challenge the status quo can reach an even larger audience through mass media if pitched tactically enough. Such technological affordances suggest a degree of merit to the "democratic thesis" regarding ICTs, that is, the idea that ICTs have enabled heretofore unprecedented access to democratic political processes (Dean, 2009). Indeed, ICTs are strongly identified "with the good of justice in liberal democratic contexts" (Barney, 2006, p. 90) because of how their proliferation brings communication and information to the masses that are "central to political life" (p. 91). Not only does the democratic thesis suggest that ICTs afford greater participation, but also that ICTs are themselves "mediating the political engagement of previously disengaged individuals" (p. 93).

NSMs and ICTs may have opened up new political arenas and therefore new ways of participating in politics, but those capacities and their democratic potential are significantly undercut by the dominance of market logics. In other words, the democratic thesis often struggles to account for the wide-reaching implications of the neoliberal socioeconomic paradigm, which seeks to reframe every aspect of life in market terms and relations (Taylor and Grey, 2014, p. 72). On a cultural level, this market emphasis is less explicit; neoliberalism celebrates the "freedom" of the individual above all else, including and especially from any sense of collective identity (Gill, 2016). In this sense, neoliberalism challenges the cultivation of collective identity that is essential to social movements. On an economic level, neoliberalism emphasises "freedom" in the market, believing that market actors should be unrestrained in the choices they can make (Hayek, 1944/2014) - so long as they have the resources to do so. Only a privileged few tend to have such a capacity. 
Instead of "saving" democracy (Dean, 2009, p. 36), neoliberalism's emphasis on individuals and the privileged few decimated the last century's largest source of collective power on the lefttrade unions. On an economic level, capitalist business owners were "freed" to operate with deregulated impunity, scaling back workers' rights wherever they can because of the profit incentives therein (Burgmann, 2016). Simultaneously, neoliberalism retrained unions' membership bases to look after themselves at the expense of the collective. Operating on both economic and cultural levels, then, union membership - and organised labour more generally - diminished dramatically (Dean, 2009, p. 65; Harbridge \& Hince, 1993; Newman \& Jess, 2014, p. 4; Ryall \& Blumenfeld, 2016). While some argue that the proliferation of ICTs can make democratic political processes more accessible, neoliberalism has simultaneously ensured that workplaces and the economy are as undemocratic as possible (Dean, 2009).

The democratisation thesis also fails to account for neoliberalism's impact on the subsequent development of ICTs. Contemporary media technologies like social media platforms are themselves structured now around neoliberal market logics. Instead of enabling meaningful political communications which contribute to the health of democracy, as the democratic thesis portends, current social media platforms are oriented around the circulation of content; users scroll through content feeds at least as much as they send messages to friends and family, while the platforms themselves profit from this activity through the data it generates (Srnicek, 2017, p. 254). So much content circulates on these platforms that the human capacity to process it all is severely limited, contributing to the 'attention economy' (Davenport \& Beck, 2001; Williams, 2018) in which social movements must compete as much as any other actor for audiences' attention. In this economy, communication itself is treated by capitalism as another "means for expropriation and exploitation" (Dean, 2014, p. 4).Such a dynamic suggests that while ICTs have become more accessible and ubiquitous than ever before in recorded history (Featherstone 2009), their utility for the many as opposed to the few remains as contested as any other part of society. Class-oriented, anticapitalist social movements, necessarily comprised of the many, must therefore walk a fine line between 
communicating effectively and succumbing to market logics in order to successfully navigate the attention economy.

Despite the impact of neoliberalism on democracy, however, recent literature has conspicuously avoided discussing the role of capitalism more generally in contemporary social movements. Gabriel Hetland and Geoff Goodwin (2013) found in their study of social movement literature that two of the most prominent journals in the field almost entirely ignored the roles of class and capitalism over a span of nearly a decade around the turn of the millennium (p. 87). Other scholars have noted the exclusion of the union movement from contemporary social movement theory as well (Luders, 2010, as cited in McAlevey 2018, p. 1), as though the defeats unions experienced at the onset of neoliberalism erased the much longer history of organised labour's relevance to the ongoing development of society.

This thesis seeks to embrace Hetland and Goodwin's critique by reinserting an analysis of class and capitalism into social movement research. By focusing on movements which are themselves oriented around working-class issues (i.e., those concerned with more materially-driven goals that benefit the working class), I seek to identify how recent developments in social movement theory might apply to contemporary class movements. I organise this thinking around the concept of 'political activation', or the process by which people progress from being disengaged from politics, to engaged, to actively participating in political affairs (Bode \& Becker, 2018, p. 1572; McDevitt \& Chafee, 2002, p. 10-11). Furthermore, I pay particular attention to how ICTs and media inform this process, since they comprise a quintessential part of how many experience the world today and often play a role in the growth of contemporary movements. How do social movement organisations focused on working-class issues use these media technologies to acquire the attention of their desired audiences? What role do these SMOs understand media to play in the political activation of those audiences? 
To answer these questions, the thesis is divided into four chapters. The first reviews recent social movement literature with attention to how the development of NSM theory and the proliferation of ICTs impact contemporary movements. This review also examines the scholarship on political activation to better understand its applicability to social movements. The second chapter details the methodology used to explore how organisers of class-based movements strategically use ICTs and other communication strategies to facilitate political activation. I base this method on the experiences of organisers who play active roles within class-oriented SMOs because their everyday attempts to cultivate the political activation of their target audiences are ideally situated for understanding how the activation process applies to social movements. The third chapter covers the findings of a thematic analysis conducted on interviews with these organisers, whose contextuallydriven and varying interpretations of their political activation processes are broken down into three key themes that facilitate political activation's reapplication outside of a civic participatory context. These themes include the sociotechnical affordances of ICTs and other communication tools, the political conflicts that both inform how each participant interpreted the affordances of the tools at their disposal and present opportunities of their own to facilitate aspects of activation, and the movement overlaps that participants ultimately sought to maximise by capitalising on those affordances. Chapter four discusses how these themes contribute to a political activation framework for social movements that is informed by the attention economy. Furthermore, chapter four considers how participants' diverse interpretations of the themes contribute to critiques of the democratic thesis. Finally, the conclusion summarises the implications of this analysis and presents directions for future research.

This thesis is principally concerned with understanding how contemporary social movement organisers build movements in a life-world saturated by media. While I have spoken so far to the bigger picture implications for this research with regards to social movement scholarship, I also sought for the findings of this research to benefit of the SMOs at its centre. One of those organisations is one that I was already myself a part of prior to this research, People Against Prisons 
Aotearoa (PAPA). ${ }^{1}$ Having been a part of the organisation for several years, I am personally invested in ensuring not only the growth of the prison abolition movement it seeks to build (see Lamusse,

Morgan, \& Rākete, 2016; No Pride in Prisons, 2017; Lamusse, 2018), but also in understanding how to more effectively build organisations and movements for the benefit of a larger political left.

${ }^{1}$ I explain in the methodology chapter how I bracketed my experiential bias toward PAPA. 


\section{Literature review}

There is a growing consensus among social movement and media scholars that the use of ICTs positively (if weakly) correlates with political engagement (Barney, 2006; Bengtsson \& Christensen, 2012; Boulianne, 2015; Lane, Kim, Lee, Weeks, \& Kwak, 2017). This correlation corroborates the work of theorists who have noted the greater range of possibilities for engagement for youth (Loader, Vromen, \& Xenos, 2014; Xenos, Vromen, \& Loader, 2014), students (Nissen, 2019; Tsatsou, 2018), the working class (Funke, Robe, \& Wolfson, 2012; Sawchuck, 2011), and other groups otherwise thought to be "disengaged" from conventional political processes (Fiorina, 2001; McDevitt \& Chaffee, 2002). Similarly, scholars originally theorised about New Social Movements on the grounds that they introduce new ways for people to participate in politics by opening up political arenas beyond factories and workplaces on the material level of society (Melucci, 1980; 1994; Offe, 1985). These developments suggest new possibilities for addressing the prerequisites for political activation.

This chapter maps out key developments of contemporary social movement literature in relation to class movements. It starts by establishing the Marxist understanding of class conflict and society on which much of the subsequent literature is also built on. I use this base to examine how NSMs have expanded on and/or challenged traditional Marxist ideas as they have risen to prominence in social movement literature and society more generally. However, I remain interested here in how these 'new' movements and the political arenas they open up continue to relate to class. The next section explores how the development of ICTs and other media technologies have enabled and/or constrained political participation. Then, I transition into exploring political activation itself in order to establish a model around which to design the research methodology. Finally, this chapter concludes by coming full circle to consider contributions from scholars examining contemporary class movements, demonstrating how this thesis accounts for and builds on understandings of those movements in the present sociopolitical context. 


\section{Marxism and class}

Numerous schools of thought regarding the nature of class have emerged from Marxism in the century and a half since the publication of Karl Marx's Capital (1867/2013). Leninism, Trotskyism, the Frankfurt school, and more have each emphasised some aspects of classical Marxism over others, but each continues to emphasise the role of capitalism in consolidating class relations (Marx \& Engels, 1848/2016, pp. 33-35). Marxist analysis typically concludes that conflicts in a society driven by capitalism derive from contradictions between the interests of the working class or "proletariat", and the ruling class or "bourgeoisie" (p. 5). These classes are characterised by their material conditions; unlike the ruling class, the working class does not own any of the means of production (capital), only the capacity to produce goods and services through the performance of labour. Consequently, the working class must sell its labour to survive. The ruling class leverages its control over capital to control workers as well by extracting the profits of any surplus labour they perform. This dynamic and the tensions therein form the basis of an ongoing struggle between the working class and the capitalist class for control over the means of production.

Marxism typically understands society as being divided into two parts: the base and the superstructure (Marx, 1859/2009). The base consists of the means of production (typically characterised in the industrial era as the tools, machines and raw materials used to produce goods and services), and the relationships between people and those means of production (e.g. as their owners or as the labourers who manipulate them). The superstructure, meanwhile, is theorised in traditional Marxism to be composed of anything else in society not directly related to production including culture, institutions and the state. ${ }^{2}$ This framework is therefore useful for identifying movements and organisations whose politics are more class-oriented through both the object of

\footnotetext{
${ }^{2}$ The idea that the superstructure is separated from production is challenged by NSM theorists, however, as discussed in the next section.
} 
struggle (control of the material base or some aspect of it) and the arenas through which that object is struggled over (worksites and state institutions such as schools, prisons and the media).

Today, however, an analysis which relies solely on a classical or orthodox Marxist methodology is widely considered reductive; critics argue that such an approach is rigidly dependent on a one-way relationship in which the base solely informs the superstructure, or else suggests that material conditions are the sole determinant of human behaviour (Pichardo, 1997; Blackledge, 2013, p. 270). Others have responded to this critique by exploring politics focused on goals which ignore the base entirely, such as those encompassed by NSMs (Melucci, 1980; Offe, 1985).

\section{New Social Movements}

Marxist schools of thought begin to diverge from the basic precepts established in the previous section over the extent of the roles the base and the superstructure play in the development of social movements. One such school of thought is that of New Social Movement theory, which emphasises conflicts over human rights, environmentalism, and other relations and social systems within the superstructure that are less directly related to class (Blackledge, 2013; della Porta \& Diani, 2006; Hetland \& Goodwin, 2013; Lievrouw, 2011; Melucci, 1980; Offe, 1985; Pichardo, 1997). Following the industrial era, during which social movements were largely considered to be "centered in the working class" (Pichardo, 1997, p. 412), new developments in modes of participation and the goals of participants in newer movements transformed the political landscape (della Porta \& Diani, 2006, p. 6). Alberto Melucci (1980) identifies this transformation as the result of society's increasing complexity; as culture and institutions continue to develop in the post-industrial area, maintaining control over them is an increasingly relevant concern for the ruling class (p. 217). Social actors seeking to contest control of these areas of society must then also extend their struggle there, resulting in a broader focus within social movements on issues framed by "quality of life" (Pichardo, 1997, p. 412) and/or "personal autonomy" (Offe, 1985, p. 849). 
Scholars present these characteristics both as an alternative to and as a critique of the previously-dominant Marxist approach to understanding social movements. At the time NSM theory first emerged, increasing dissatisfaction with the Marxist approach revolved primarily around a perception of its economic determinism, which was thought to focus unduly if not entirely on "productive forces" (della Porta \& Diani, 2006, p. 6), "dynamics of class relations" and/or the "preconditions of revolution" (Melucci, 1980, p. 199). Because a traditional Marxist approach focuses on these qualities, critics argue that it ignores the social movements that build toward said revolution, glossing over a key component of what could be a more holistic theory (della Porta \& Diani, 2006, pp. 6-7; Melucci, 1980, p. 199).

To begin understanding the role of social movements in a post-industrial society, Melucci (1980) distinguishes between three types of movements, of which only one specifically addresses class. The first of these movement types is an "organisational movement", which is largely contained to an organisation that is directing activity "against the power governing a system of norms and roles" (p. 203). This definition does not specify whether its "norms and roles" are in relation to labour, opening up the possibility for other forms of politics. The second movement type, "political movement", is characterised by a move from those organisations to "collective actions which tend to enlarge political participation" (p. 203). Political movements also include but are not necessarily limited to class politics. Finally, Melucci considers "class movements" as a category distinct from (but overlapping with) the first two movement types, given that they "fight for... a distribution of social resources different from the particular one effected by the dominant class" (p. 207). ${ }^{3}$ NSMs, on the other hand, may be identifiable as organisational movements or political movements, but because their participants are not as necessarily united by a shared class position (i.e., fighting a "dominant class" and its resource distribution), they are distinguishable from class movements.

\footnotetext{
${ }^{3}$ Class movements in Melucci's terms require organisational and/or political components, however; without them, class movements "turn easily to counter-cultural action or violent marginality" (p. 205).
} 
Through this framework, Melucci argues that NSMs do not have the same critical mass as movements driven by an entire class (p. 207). Instead, NSMs emphasise more individualised, rightsbased projects which define their politics through "issues other than class" (Lievrouw, 2011, p. 153), and often focus on more socially determined identities like gender, sexuality and race (West, 2004, p. 265). In the following decades, these shifts in movement structure and purpose resulted in such landmark historical moments as the American Civil Rights Movement (McAdam, 1999; Zhang, 2002), the international gay liberation movement (D’Cruz, 2014; Hetland \& Goodwin, 2013; Lewis, 2016) and, more locally, the Māori Renaissance (Kennedy, 2016; Taonui, 2017). Such movements differ greatly from their more class-oriented predecessors by emphasising struggles in cultural arenas, social relations and social systems over struggles for control over the means of material production.

Another key quality of NSMs is their common (but not universal) tendency to centre issues pertaining to the body. Melucci (1980) notes how antiracist, feminist and queer movements in particular frame the body as "the nexus of interpersonal relationships", which is simultaneously "an object upon which the concerted integrative and manipulative efforts of the system of domination are focused" (p. 221). In other words, bodies themselves comprise a political arena. Exemplified by the second-wave feminist adage that 'the personal is political' (Dean, 2016b, para. 4), bodies signify the cultural norms and roles that are understood through sexuality and other social relations (Melucci, 1980, p. 221). NSMs frequently orient themselves around the politicisation of the private sphere as much as the public, beginning the process of collapsing them into each other (1994, p. 101). However, critics argue that this expansion of politics is vulnerable to distortion by neoliberal ideology (Dean, 2016b; Gill, 2016). Its cultural emphasis on individualism becomes compatible with NSMs because of the individuation that occurs when the body is rendered political. Rather than denoting individuals' social relations and position within a larger social system, a neoliberal interpretation of such politics emphasises the individual as a discrete unit, prioritising that unit over who and what it is related to (Dean, 2016b). Any tendency toward collectivity is disrupted when the 
individual is considered in a vacuum (and even, Dean argues, when considering the individual discretely at all [p. 113]).

NSM theory considers movements characterised by a shift away from class concerns. However, this separation is rarely total. Hetland and Goodwin (2013) model their analysis of the role of class and capitalism in the LGBT movement after similar work done by scholars of the American Civil Rights Movement, finding that in both cases, the "emergence of a collective and publicly visible" identity in relation to that movement was dependent "upon the expansion of wage labour" (p. 93). These findings suggest a continued connection to class and material concerns rather than a break from them (Pichardo, 1997, p. 414). Further, Hetland and Goodwin argue that class divisions within the LGBT movement are becoming more apparent over time, and that NSMs "have come to reflect more and more fundamentally the class of the people who dominate them" (Hollibaugh \& Singh, 2001, as cited in Hetland \& Goodwin, 2013, p, 98). Similarly, Jodi Dean (2016a) suggests that a "preference for the crowd" is re-emerging (p. 64), lending greater credence to the idea that while the politics of NSMs can be divorced from class-based issues when the individual is overemphasised, class remains a relevant factor to identity-based issues.

\section{Technological developments}

The emergence of information and communication technologies which enable "diverse means and practices for engaging in public life" also inform the development of political participation in recent decades (Barney, 2006, p. 89). The distinction between online and offline political organising is "sometimes relevant" now, but "more often not" as those practices begin to overlap in daily life (Bennett \& Segerberg, 2012b, p. 749). As with NSMs' contributions to the expansion of political consciousness into private as much as public life, so too have these emerging technologies opened up new avenues for political participation. For example, Brian D. Loader, Michael Xenos and Ariadne Vromen examine how social media use correlates with [a broad 
definition of] political engagement, arguing that "most acts of political engagement can and are carried out within social media" today (p. 164). To some extent, the "participation in social movements, rallies, protests, [and] consumer boycotts" they describe as youths' alternatives to conventional civic political participation all have the capacity to involve social media (Xenos et al., 2014, p. 143). Lance W. Bennett and Alexandra Segerberg theorise that this kind of involvement is constitutive of "connective action", or a type of action focused on the cultivation of networks for which digital media are a "core organizing agent", though "old-fashioned [offline] meetings, issuebrokering and coalition building" persist (2012b, pp. 749, 752). These studies each attribute technological developments to the accessibility of information and communications.

A key tool for understanding how these technologies inform the accessibility of information is the concept of 'affordances'. Though the concept is used in a wide range of disciplines, Taina Bucher and Anne Helmond (2018) define affordances as "what material artifacts such as media technologies allow people to do" (p. 4). Ian Hutchby's (2014) definition is more expansive, suggesting that affordances are "both functional and relational: functional in that they enable (and also constrain) ... the conditions of possibility associated with an action," and "relational, in that they may differ for one object in different contexts" (p. 87, emphasis in the original). The concept of affordances therefore helps identify what objects like social media platforms are actually capable of enabling for their users. Hutchby further delineates between affordances more generally and "communicative affordances", which concern the impact of media technologies on communication itself (p. 87).

The concept of affordances therefore helps to explain how post-industrial economies can be based on the "production and processing of information" (Melucci, 1994, p. 101). The technologies built by those economies enable such comparatively easy production and distribution of information that information is no longer presumed scarce. Rather, information's abundance is instead contrasted with the comparative scarcity of the human attention span that constrains the ability to 
process information (Davenport \& Beck, 2001; Williams, 2018). In this 'attention economy', actors compete less over access to media technologies to gain the attention of their desired audiences and more over the attentional capacities of those audiences (Williams, 2018, pp. 15-16). So plentiful a resource is information in the attention economy that Ruud Koopmans (2004) suggests there are three "selection mechanisms for the public sphere" (p. 373) that determine the information to which an audience should devote their attention. These mechanisms include visibility, which involves how much coverage an actor's message attains within the media; resonance, which concerns the extent to which other actors in the public sphere react to that message, either positively or negatively; and legitimacy, which measures how much the public supports or rejects that message, regardless of how resonant the message is (pp. 374-375). Social movement organisations are as beholden to these selection mechanisms as any other actor seeking to produce and transmit information in exchange for attention, rendering attention itself a currency (Davenport \& Beck, 2001).

The development of the attention economy has dramatically impacted the purpose and outcomes of communication itself. However, Dean (2009) argues that the formation of the attention economy under a capitalist mode of production has fundamentally undermined the use value of communication by reinterpreting the process in economic rather than social terms. Rather than "saving democracy by bringing technology to the people", as proponents of the democratic thesis purport (p. 36), the exchange value of a message is prioritised instead of its use value in a system that Dean calls "communicative capitalism" (pp. 26-27). As a result, communications no longer comprise "actions which elicit responses" (p. 26), but content which circulates a communicative market as a commodity. Rather than contain messages, Dean argues that this content is characterised by "empty signifiers" which represent meaning but are devoid of it (p. 42), consolidating a "democracy that talks without responding" (pp. 21-22).

The platforms through which this content circulates exacerbate these qualities of communicative capitalism. Eli Pariser (2011) looks at how Facebook introduced the "Facebook 
Everywhere" feature in 2010, which "made it possible to press the Like button on any item on the Web" (p. 39). This feature highlights the internet-wide scale on which personalisation now operates to supposedly better understand users' preferences based on what they Like-not just through Facebook, but anywhere online. Personalisation through data input like this has two consequences. Firstly, personalisation feeds platforms' "insatiable" appetite for data (Srnicek, 2017, p. 256) by facilitating the circulation of content and other goods, thus financially incentivising those platforms to continue extracting information about their users. Conventional business wisdom dictates that "the more personally relevant [platforms'] information offerings are, the more ads they can sell, and the more likely you are to buy the products they're offering" (Pariser, 2011, p. 7). Secondly, while personalisation may constitute a filter through which to process an "overwhelming torrent" (pp. 1011) of information produced by the attention economy, acquiring relevant information is no guarantee that the user will act on that information in a political context. Darin Barney (2006) argues that doing so actually "immobilizes [people] precisely because they are informed" (p. 96, emphasis in the original). Valuing the acquisition of that information over acting on it once again emphasises Dean's idea that the exchange value of content is emphasised over the use value of what that content seeks to communicate (2009, pp. 26-27). In a political context, personalisation only serves to make the circulation of content even more valuable to platforms, requiring social movements to demonstrate "increased lay-knowledge and a playful awareness of how media operate" (Cammaerts, Mattoni, \& McCurdy, 2013) in order to fully capitalise on the affordances of such technologies.

While the proliferation of technologies that can produce, distribute and accumulate information enables a range of new political opportunities, so too do a new range of psychological, economic and communicative constraints endemic to the attention economy described above complicate how social movements can use those technologies to political ends. Social movements and organisations contributing to them now have equal access to ICTs, but successfully reaching audiences, resonating with them, and convincing them to participate requires careful navigation of 
the attention economy. Once movements acquire sufficient attention to grow their audiences, however, ICTs enable more means than ever for people to "create networks, structure activities, and communicate their views directly to the world" (Bennett \& Segerberg, 2012b, p. 749) in ways that involve interaction "with others, not just screens" (Dean, 2016a, p. 66). Doing so ensures that "the idea of a message as something sent by a speaker to a receiver in order to elicit a response" (Dean, 2014, p. 6) can continue to "service the virtues of political judgment and action" (Barney, 2006, p. 97).

\section{Political activation}

Political activation, or the process by which people become active participants in political affairs (Bode \& Becker, 2018, p. 1572; McDevitt \& Chafee, 2002, pp. 10-11), is not closely associated with social movement research. When scholars do deploy the concept, it is often operationalised in quantitative research (Bode \& Becker, 2018) and/or used to explore narrowly-defined forms of civic participation (McDevitt \& Chaffee, 2002). Its application to social movements is therefore underexplored; despite components of the activation process (e.g., capacity and mobilisation) consistently receiving scholarly attention (Bengtsson \& Christensen, 2012; Lievrouw, 2011), those components are typically examined on their own merits rather than as part of a larger whole. However, by collating those components into a larger theoretical structure, political activation can model what social movements do to "enlarge political participation" (Melucci, 1980, p. 203) enough to achieve their goals (McAlevey, 2018, p. 13).

Though they conflate "activation" with "participation", Leticia Bode and Amy Becker (2018) develop a generally applicable model for political activation that treats it as a series of somewhat nonlinear prerequisites, including the "capacity", "motivation", and "mobilization" of potential 
participants (p. 1574). ${ }^{4}$ Capacity in this sense involves having the abilities or skills necessary for participation, but also the knowledge that doing so can have a political effect (p. 1575); motivation concerns the degree to which someone is incentivised to participate (p. 1574); and mobilisation is the "simple act of being asked to participate", which requires some degree of capacity and motivation (p. 1575). However, while Bode and Becker review these concepts together, other scholars consider them individually and do not necessarily address their connection to political activation more broadly. For example, Åsa Bengtsson and Henrik Serup Christensen (2012) address capacity specifically, but frame it instead as the "competency" of citizens who conduct political activities in ways that have "efficacy" (p. 131). Similarly, Leah A. Lievrouw (2011) looks at how mobilisation is "mediated" today by ICTs which "promote radical and participatory democracy, where participatory democracy is defined as the widespread, direct involvement of citizens in both political processes and governance" (p. 149). Though Lievrouw looks at the role mobilisation plays in larger participatory political processes, she too avoids looking at mobilisation as part of a larger model for activation. Where Bode, Becker and other political activation scholars tend to overlap with those focused on its individual parts, however, is that motivation tends to be the hardest aspect of political activation to pin down. Bode and Becker cite research suggesting that motivation is "difficult to move" (Prior, 2010, as cited in Bode \& Becker, 2018, pp. 1574-1575); Lievrouw alludes to motivation by acknowledging how "unpredictable" mobilisation is (2011, p. 154); and other scholars consider how such unpredictability reflects how mobilisation involves factors and contexts which are highly specific - personalised, even - to each individual (Bennett \& Segerberg 2012b).

While Bode and Becker's activation model is generalisable enough that its components resonate with other literature, other political activation scholars develop more nuanced models that specifically reflect the context of their case study. For example, Michael McDevitt and Steven H. Chaffee's (2002) study on working class families provides insight into how that particular

\footnotetext{
${ }^{4}$ Bode and Becker note, however, that meeting these prerequisites does not guarantee participation.
} 
socioeconomic context produces specific opportunities for activation. Through a civics education programme introduced at the families' nearby school, children engaged with their parents in ways which led to increased interest in civic involvement and a progression through five stages of activation (as opposed to Bode and Becker's three prerequisites). To start, participants in the study 1) engaged in "information seeking", followed by 2) increased political discourse within the family that 3) pressured adult family members to increase their own political literacy (p. 25). Then, family members 4) developed the capacity to maintain interest in political affairs, which finally led to 5) increased motivation to participate outside the family home (p. 25). McDevitt and Chaffee's model is informed by the specific social dynamics of the family, demonstrating political activation's applicability/adaptability to specific social contexts.

Such flexibility is necessary for adapting the concept of political activation to the context of social movements. Political activation literature is primarily interested in civic participation, or participation in institutionalised democratic processes like voting, contacting political representatives and participating in public discourse (e.g., Bengtsson \& Christensen, 2012; Peterson, 2010); the concept has not been applied before to social movements, which encompass a wider range of more protest-oriented political activities including pickets, blockades and other forms of civil disobedience designed to make everyday voices heard. However, research suggests that civic participation is increasingly being superseded by participation in social movements. Sylvia Nissen (2019) suggests that young people today have a "collective willingness to explore new ways of engaging politically" which stems from their "dissatisfaction with the status quo" (pp. 115-116). Loader, Vromen and Xenos (2014) consider this willingness a new norm of sorts for younger generations, taking the idea so far as to suggest a "possible displacement of traditional models of representative democracy as the dominant cultural form of engagement" (p. 143). Thus, the increasing relevance of participation in social movements to democratic political processes (della Porta \& Diani, 2006, p. 6) further justifies the application of a political activation model to social movements. 
An understanding of what constitutes political activity is also required for understanding how this thesis deploys the concept of activation. The work of Hannah Arendt (1958) has enduring contemporary relevance on this front. Arendt distinguishes between three forms of activity - labour, work, and action - that comprise the vita activa, or "active life". Labour concerns the repetitive and necessary tasks associated with reproduction of the ability to do more labour; work considers only activities that have specific means and ends; and action is the means by which humans "disclose" themselves to others (pp. 179-180). Though action is of particular interest to social movements because of its inherently social nature, any activity (labour, work, or action) contributing to a social movement counts as activity for the purpose of this thesis. Put another way, the reproductive labour required to provide victual sustenance for participants of a protest action like a march is just as essential to a social movement as the work put in by the organisers to organise that action.

In order to strengthen the links between political activation and social movements, I turn now to the techniques deployed by movements themselves in order to cultivate political participation. Key among these is the use of frames (Berenson, 2018; McAlevey, 2018), and action frames in particular (Benford \& Snow, 2000; Bennett \& Segerberg, 2012a; 2012b). Action frames "help to render events or occurrences meaningful and thereby function to organize experience and guide action" (Benford \& Snow, 2000, p. 614), speaking on some level to the capacity and/or motivations required to mobilise. Movements are inclined to frame all their activities in terms of the "sets of beliefs and meanings that inspire and legitimate... a social movement organization (SMO)" (Benford \& Snow, 2000, p. 614), as doing so is one of the most straightforward ways they can encourage participation on a discursive level.

However, more recent literature looks at the emergence of more "personalised" action frames that target individual, more refined sets of beliefs that are often organised around culturallylocated identity categories over a more general audience. Bennett and Segerberg (2012b) note how contemporary movements rely on these personalised action frames to mobilise people because "the 
identity reference is more derived through inclusive and diverse large-scale personal expression rather than through common group or ideological identification" (p. 744). This personalisation ensures a degree of "mutability" between movements, as participants are more easily able to move between them without having to fundamentally shift their own individual identities to align with collective ones (Lievrouw, 2011, p. 153). Notably, personalised action frames like these are highly compatible with NSMs, particularly those engaged in more embodied political arenas that therefore engage participants on a personal rather than collective level.

This personalisation tends to come at a price for the collective identity formation upon which even these NSMs rely (Lievrouw, p. 153). Evgeny Morozov (2011) argues that the motivations for activity communicated through ICTs have less to do "with one's commitment to ideas and politics in general" than they do with "impressing one's friends" (p. 186). Similarly, Bennett and Segerberg (2012a) describe a "growing demand for personalized relations with causes and organizations" that has rendered ICTs even more central to social movement organising because of their ability to customise the individual's relationship to the cause-not necessarily to connect the individual to others within the movement (p. 14). Consequently, this understanding of the role of ICTs in political activation is individualised, rather than built on a collective of interpersonal relationships, which presents "a set of fundamental challenges, chief among which concerns negotiating the potential trade-off between flexibility and effectiveness" (2012a, p. 14). In other words, if a movement's many participants each have their own motivations for participating, and those motivations inform differing ideas about how to pursue the movement's goals, how does that movement coherently agree on a set of demands and organise toward them? How can individualised participants form a class movement if their collective identity is "of a class, but not on behalf of a class", as Claus Offe observes (1985, p. 833)? Given the general absence of class and capitalism from political activation as much as other social movement literature, the final section of this chapter considers the literature that actually does emphasise the concepts of class and capitalism in the context of contemporary social movements. 


\section{Contemporary class movements}

As Hetland and Goodwin argue, contemporary social movement literature frequently ignores the influences of class and capitalism on movements, influences which even extend to NSMs that are not directly organised around those concerns (2013, pp. 100-101). Others point out how this exclusion is conducted at the expense of entire movements, when those movements are explicitly oriented around class like the union movement (Luders, 2010, as cited in McAlevey, 2018, p. 1). Political activation research is no exception to this erasure, as its general focus on civic participation in democratic political processes largely neglects the material reasons for the growing dissatisfaction with establishment politics (Edelman, 2018); namely, that they continue to facilitate a growing wealth divide (Burgmann, 2016; Hardoon, Fuentes-Nieva, \& Ayele 2016; Groot, Van Ommen, Masters-Awatere, \& Tassell-Matamua, 2017, p. 9). The general disappearance of capitalism and class from social movement research therefore makes exceptions to the trend essential inclusions to this literature review, if Hetland and Goodwin's call for a resurgence of class analysis is to be heeded.

The first of these key exceptions is Jane McAlevey (2018), who contends that the failures of the political left in recent decades are attributable to shifts in strategy away from mass mobilisation. She opens her book No shortcuts: organising for power in the new gilded age with an anecdote about the "pollsters" who, she argues, have displaced union organisers within left-aligned political organisations in recent decades (p. xvii). These pollsters and their overreliance on "polling and big data... frames and messaging" exemplify the "shortcuts" alluded to in her book's title because they avoid the work of engaging directly with the working-class base of the union movement (p. xviii). Similarly, Dean (2009) asserts that politics more generally have transformed into "a domain of financially mediated and professionalized practices centered on advertising and public relations" ( $p$. 24). In other words, both authors argue that even left-aligned political organisations now rely on the 
dissemination of communications from their elites. ${ }^{5}$ McAlevey calls this top-down approach to politics an "advocacy" model, which involves "heavy spending on polling, advertising, and other paid media", and an entirely elite rather than mass movement base (p. 11). She contrasts this model with a "mobilizing" one, which involves relying on a base of the same activists who "show up over and over" to political actions (p. 12), and an "organising" model in which "frames matter, but the numbers [of people] involved are sufficiently compelling to create a significant earned media strategy" (p. 11). These "options for change" summate the distinctions between the top-down politics deployed more recently by the left and more traditional union movement strategies, but McAlevey says little about the role media should play in class struggle beyond reaffirming the importance of action framing in media discourses on said struggle (pp. 166-167). The increasing mediation of politics is not necessarily to blame, then, for a failure to engage with class issues. Rather, it suggests that political organisations like the ones McAlevey criticises fail to do so by facilitating the organisation of a political class movement, the kind Melucci (1980) considers to "not only aim at enlarging political participation, but which also directly challenges the hegemony of the dominant political forces and their link with class interests" (p. 204).

Similar patterns of problematic framing exist more locally, too. Also referencing Hetland and Goodwin's (2013) call for more analysis of capitalism in social movement studies, Dylan Taylor and Sandra Grey (2014) conduct an analysis of the media publications of class-based organisations representing "workers, the unemployed, and the poor" in Aotearoa/New Zealand (p. 69). They find that the literature's gravitation away from talking about class and capitalism corresponds to a disappearance of those same topics from union publications during the onset of neoliberal reforms in the country, even as discourses on class and capitalism persist in more radical socialist and communist equivalents (p. 81). Union publications began to displace class in favour of trying to "include identity groups" in their action frames (p. 80), which Taylor and Grey argue constitutes a

\footnotetext{
${ }^{5}$ And of course, those communications are themselves subject to the circulating and filtering mechanisms of ICTs under communicative capitalism.
} 
reaction to the fragmentation of the political left rather than a sign of strength as the union movement incorporates the NSMs emerging from those identities. As a result, unions and socialist/communist groups "ceased to speak the same language from the 1990s onwards" (p. 82), despite ostensibly retaining similar political goals. The way class politics are communicated has also undergone significant transformation.

Where others looking at class movements critique the erasure of class-based political strategies both within the union movement and within its media, Peter N. Funke, Chris Robe and Todd Wolfson (2012) instead explore the role of media in building up working class power. Their case study explores how media can combine cinematography and ideology into a shared site for the production of a working-class subjectivity. The Philadelphia-based media production collective comprising Funke et al.'s case study tries to "suture fragmented groups of workers into a class formation that can begin to resist and challenge" the ruling class (p. 16). Such a project subverts the top-down tendencies of the unions described by McAlevey, Taylor and Grey above by working on media with the base as participants rather than (or perhaps as much as) audiences. Furthermore, the case study also circumvents the commodifying effects of communicative capitalism by mandating face-to-face interactions in the service of media production, sidestepping the tendency for digital messages to be commodified and circulated instead of communicated. Further still, the second half of the case study features a textual analysis of the films produced by the Philadelphia group, implying that its participants became more effective at suturing a more cohesive, cross sector, working-class subjectivity over time. Though Funke et al. acknowledge that this effectiveness is restricted to contexts where "communities and subjectivities were already forming", the suturing process is nevertheless enhanced by its mediated components (p. 27). Such possibilities suggest that the relevance of class politics has not only not diminished in a contemporary setting, but that the possibilities for media use in class movements remain significantly underexplored. 


\section{Conclusion}

The diversification of politics and means of engaging with them in the post-industrial era are constrained in no small part by the attention economy. Despite expanding into new political arenas (e.g. the body as it is addressed by feminist, queer and antiracist NSMs) and through new technologies (e.g. social media), it seems that the capacity to process all the information circulating about politics has a human limit. As a result, Dean (2009) argues that these new means of engagement too often exemplify the "democracy which talks without responding" at the heart of communicative capitalism (p. 22), undercutting the potential of individual contributions to influence democratic political processes. Similarly, McAlevey (2018) articulates how an overreliance on media by political elites turns the masses into passive audience members that elites [supposedly] work for in a representative capacity, significantly undercutting one of the greatest strengths of the political left: participation of the masses (p. 9).

In this context, the utility of political activation as a model for finding new ways to facilitate engagement is of increasing significance. By collating the different prerequisites for participation/activation (capacity, motivation and mobilisation), it becomes possible to see not only how aspects of NSMs and ICTs enable and/or constrain political participation, but precisely which prerequisites for activation they affect. Furthermore, applying such a model to contemporary class movements addresses the dearth of research covering the influences of class and capitalism on recent social movements (Hetland and Goodwin, 2013) by exploring how class-based SMOs use ICTs to navigate an attention economy characterised by communicative capitalism. By filling these gaps, this research therefore has the potential to better understand the role that ICTs can play in building movements that are driven by a "majority" of people (McAlevey, 2018, pp. 12-13), and are therefore "of a class" rather than "on behalf of" one (Offe, 1985, 833). The next chapter elaborates on how each of these considerations ultimately informed the research methodology I used to further explore the potential for media use in the political activation of the working class. 


\section{Methodology}

Multiple scholars have suggested that proliferating information and communication technologies and their affordances for political participation have the capacity to generate minor net increases in political interest and activity (Boulianne, 2015; Castells, 2007, p. 249; Christensen, 2011). However, others have found that sustained increases in individuals' interest in politics are inconsistent, depending on short-term variations in contexts like election cycles (Prior, 2010). Furthermore, other scholars argue that while those ICTs enable new means of political participation, they simultaneously limit the extent to which people are willing and/or able to mobilise (Barney, 2006; Dean, 2009; Morozov, 2011; Williams, 2018), raising questions as to their overall merits with regards to organising social movements. Within this context, I ask again: how do social movement organisations focused on working-class issues use media to acquire the attention of desired audiences? What role do these SMOs understand media to play in the political activation of those audiences? To answer these questions, which requires understanding how movements navigate the constraints of the attention economy, I argue that it is worthwhile to consider the experiences of organisers from contemporary SMOs who must do so on a regular basis. By involving organisers in this research and drawing on their experiences, I am better enabled to identify, analyse, and propose further developments on strategies for overcoming obstacles to movement-building that are inherent to the attention economy.

This chapter is divided into three sections, which together outline a methodology used to apply a political activation model to analysis of the media and communication practices of contemporary class-based social movements. The first section outlines my theoretical framework, which establishes the Marxist analytical tools that I use to explain and situate how this research defines and deploys the concept of 'class'. This framework also establishes how such tools remain applicable to the $21^{\text {st }}$ century, characterised as it is by NSMs and ICTs. The second section then describes the sampling, recruitment, and interview processes used to collect data for analysis, as 
informed by the theoretical framework. Finally, the third section describes the data analysis process and how it produced results capable of answering the research questions.

\section{Theoretical framework}

Azadeh Osanloo and Cynthia Grant (2016) consider the selection of theoretical frameworks to not only be the process that determines research's guiding structures, but a reflection of the values informing that research (p. 19). As such, I embrace theory that is philosophically aligned with the class-based social movements at the centre of this thesis. Such an alignment prioritises Marxism, though it is also informed to some extent by NSM theory in order to scope down to and identify contemporary class movements for the research sample.

Marx's (1867/2013) definition of class - that it is determined by one's relationship to the means of production - is fundamental to identifying class-based social movements. Because class movements are primarily concerned with control over production, they are historically understood to be "orientated to the seizure of state power" (Blackledge, 2013, p. 259) through which they can ensure that the means of production serve the interests of that class (Marx \& Engels, 1848/2016, p. 47). On at least one level, class movements are identifiable through how strongly their goals relate to means of control over production. However, as Melucci's (1980) groundwork for NSM theory establishes, the parts of society that can be considered "productive" have expanded so much in the post-industrial era that entire industries are now centred around the production, processing and distribution of nonmaterial goods such as information (Melucci 1980; 1994; Srnicek, 2017; Williams, 2018). These conditions are the basis for the emergence and prevalence of NSMs, which must be differentiated from class-oriented movements in order to build the research sample. In practice, the movements qualified for the sample also exhibited some NSM qualities, but were ultimately oriented toward control of the means of production somehow. 


\section{Data collection}

Scoping the sample

The widening gap between the rich and the poor in Aotearoa/New Zealand and the world over (Groot et al., 2017; Hardoon et al., 2016) lends a degree of urgency to the prospect of reinvigorating the political participation of the working class (McDevitt \& Chaffee, 2002; Sawchuk, 2011). Because the research questions revolve around the latter concern in particular, I narrowed the scope of the organising models I would have to account for to class-oriented movements that see their goals as ultimately contributing to control over the means of production. I further narrowed the scope by confining my sample to Aotearoa/New Zealand, which I did both because of geographic constraints and due to my involvement with class-based SMOs in the country prior to this thesis. This background increased my likelihood of gaining access to and recruiting participants. Through my previous involvement with such SMOs and their networks, I also acquired a general knowledge of similar organisations across the country that I deployed here. In short, I started building my potential sample from what I already knew.

While recruiting, I found that one of the larger local organisations I approached that purported to address class issues (amongst several others less directly oriented around class) had a more complex bureaucratic structure that I experienced some difficulty navigating. In the end, this organisation did not agree to work with me. In contrast, the other three organisations I approached, which were smaller in terms of their membership and structural complexity, did not have these qualms and were much more willing to participate. Furthermore, these smaller organisations had more explicit ties to and a greater focus on class movements given that class-related issues were their primary areas of concern rather than one among several. Such priorities suggested that these smaller organisations' perspectives would ultimately be more relevant to this research's focus on class. 
To address political activation through the perspectives of these smaller class-oriented organisations, I prioritised a sample which spoke to a range of working-class experiences and conditions, and which in some cases exhibited some NSM traits as well. The participants comprising the final sample are described below:

- Unions Wellington (UW) is the Local Affiliate Council for the New Zealand Council of Trade Unions (NZCTU). Established in 1987, its formal membership is comprised of a handful of organising roles, like a convener, as well as representatives from each of the region's affiliated trade unions ${ }^{6}$. This formal membership convenes to coordinate the efforts of their unions on a cross-sector level for the common good of all workers (NZCTU, n.d.). Informally, however, UW's current iteration also adopts a more open, collaborative approach to building the union movement by inviting anybody - even non-union members - to participate in its meetings and actions. On this level, the organisation seeks to advance workers' interests in contexts where unions themselves are less able to, such as through supporting local workers' industrial actions on the ground and through the media even when they are unaffiliated with a union. UW's goal is to build a union movement with a broad scope for understanding what constitutes a worker's issue, which increasingly overlaps with NSM issues like environmentalism; UW shares concerns with local environmental SMOs' regarding industrial sustainability and its impact on workers, as evidenced by how both movements speak to each other's politics in their own media (Oil Free Wellington, 2018a; 2018b; Unions Wellington, 2018).

- People Against Prisons Aotearoa (PAPA) is a national, volunteer-driven organisation campaigning for a programmatic series of demands designed to weaken New Zealand's criminal justice system. The organisation's long-term goal is the complete abolition of that system, and the establishment of alternatives to prison (Lamusse et al., 2016). The

\footnotetext{
${ }^{6}$ The CTU has 27 affiliates nationally, though not all have a presence in Te Whanganui-a-Tara/Wellington.
} 
organisation connects its work with prisoners to the working class by citing research which claims that poverty-driven crime is the basis for an overwhelming majority of incarceration, and that the prison itself is a tool for the ruling class to exercise control over society (e.g. Reiman \& Leighton, 2015). PAPA therefore sees prison abolition as a necessary step toward building a working-class movement that can seize control of the means of production from that ruling class. The organisation started as a horizontal network named No Pride in Prisons (NPIP), which coordinated protest actions across Tāmaki Makaurau/Auckland in 2015 on behalf of transgender prisoners specifically (No Pride in Prisons, 2015). That network has since evolved into a national organisation encompassing more than 50 active members and hundreds of supporters across the country who have developed a prisoner pen pal network, a prisoner advocacy service, and an education service on alternatives to the prison system. The organisation believes that capitalism is the reason prisons exist in Aotearoa, and therefore sees prison abolition as a component of a larger working-class movement toward the end of capitalism as well (People Against Prisons Aotearoa, n.d.). I have been organising for PAPA since 2016, when it operated under its previous name and still exhibited more queer- and trans-focused NSM qualities than class-oriented politics.

- $\quad$ Auckland Action Against Poverty (AAAP ${ }^{7}$ ) is a Tāmaki Makaurau/Auckland-based organisation dedicated to "mobilising against the neoliberal agenda on jobs, welfare and poverty" (Auckland Action Against Poverty, n.d.). Founded in 2010, the organisation generally forefronts the needs and struggles of beneficiaries within New Zealand's welfare system through education, advocacy and direct action strategies. Many of these beneficiaries fit the Marxist definition of working-class through the capacity to perform labour and lack of ownership over capital, even if they are not actually working. More importantly, however, the increasing precarity of work is defined by insecure employment, wages and access to benefits (Groot et al., 2017; Standing, 2014). The way AAAP frames its

\footnotetext{
${ }^{7}$ Referred to colloquially as "Triple A.P."
} 
politics therefore suggests a convergence of working and nonworking categories that moots the distinctions between them for the purpose of this research. AAAP hosts open days to provide advocacy services and weekly political discussion meetings from its office space in the city, as well as seasonal "community events" that are hosted in public spaces. The organisation has around 50 active members and organisers, most of whom are beneficiaries themselves. They network with beneficiaries in the queues outside Work and Income offices, directly advocate for those people inside those offices, speak to the press alongside them, and occasionally mobilise the organisation's wider support base for protest action. All of these activities are part of a wider strategy to improve the material conditions of Tãmaki Makaurau/Auckland's working class.

The working, nonworking and incarcerated experiences these three groups organise around speak to a range of issues relevant to working-class experiences, which as UW and PAPA demonstrate also includes issues typically addressed by NSMs. The organisations' primary orientation, however, remains around class issues, ultimately positioning them within scope for the research sample.

\section{Recruiting participants}

The research questions specifically ask how these organisations use media, and the role that their media strategies might play in the political activation of their target audiences. To best answer these questions, I sought research participants that specialised in some aspect of their organisations' media work, outreach and/or recruitment practices. In order to build relationships with and recruit individuals within the sample SMOs that met these criteria, I found it useful to leverage my previously existing positionality as a fellow SMO organiser. However, familiarity alone was not enough for me to successfully recruit participants, as the accessibility of the potential participants proved to be an obstacle for material reasons as well; these organisers are largely unpaid for the work they do on behalf of their SMOs and do that work on top of a day job or study. Though 
volunteers for these smaller organisations were eager to participate, I still needed to build up a strong enough rapport to convince them that participation was worth their limited time.

To build this rapport, I took the local context of my sampling efforts into account, which included the cultural considerations that would best integrate me into the communities/organising cultures of potential recruits - another advantage of having an existing familiarity with the field (Johl \& Renganathan 2010, p. 45). These considerations included the adoption of select tikanga Māori ${ }^{8}$ practices throughout the recruitment components of this methodology, which I saw value in for two reasons. Firstly, my prior experience with left-aligned SMOs (including but not limited to PAPA) is what led to my initial exposure to tikanga; many of the organising spaces I entered ascribed significant value to such practices. Drawing on this experience, I decided that adherence to tikanga would be beneficial to building relationships with potential participants. Secondly, my commitment as a researcher to uphold Te Tiriti o Waitangi/The Treaty of Waitangi mandates the preservation of taonga ${ }^{9}$, which includes the terminology and concepts expressed through te reo Māori ${ }^{10}$ (Lang, 2011, p. 9), including tikanga. Adherence to Te Tiriti/The Treaty also fundamentally requires engaging with - rather than ignoring and/or avoiding - Māori on their terms (p. 1). Tikanga are integral to this process, as “'tika' means 'to be right' and thus tikanga Māori focuses on the correct way of doing something" as determined through frameworks developed by Māori (Mead, 2016, pp. 13-14). Incorporating tikanga into this methodology therefore ensured that I could a) engage with and uphold the Treaty, and b) better interact with potential participants and organisations in a culturally congruent manner. ${ }^{11}$

\footnotetext{
${ }^{8}$ Correct procedure, practice, protocol, as determined by Māori.

${ }^{9}$ Treasures.

${ }^{10}$ Māori language.

${ }^{11}$ My own positionality is also relevant to understanding why I chose to engage with te ao Māori (the world of Māori) in this way. I descend from a Pākehā (white European settler) family that has been in Aotearoa/New Zealand for many generations. However, there are also significant gaps in my family's knowledge of that whakapapa, especially on one side where there are no clear first-generation settlers, casting my relationship to te ao Māori into existential doubt. The reason I know this at all, however, is through practicing tikanga after
} 
In particular, I applied two aspects of tikanga which were directly applicable to the recruitment process: kanohi ki te kanohi ${ }^{12}$, which values "physical presence and even a sense of commitment, to whānau ${ }^{13}$, to a land, to a kaupapa ${ }^{14 "}$, and kanohi kitea ${ }^{15}$, which values "'being seen' to strengthen relationships and one's place of belonging in the community" (O'Carroll, 2013, p. 229). I consciously applied these concepts to my interactions with organisations both before and after they agreed to participate, with the exception of the larger organisation that refused, as it did not have clear public meeting spaces for me to access them from while applying this method. I prioritised not only attending, but actively participating in meetings and actions, contributing to the activities therein and engaging with people there in a face-to-face capacity. This approach worked the most successfully with Unions Wellington, at whose meetings I became acquainted with the 'convener' responsible for the organisation's press, social media and other communications. They ${ }^{16}$ agreed to participate after a kanohi ki te kanohi conversation about this research.

I experienced a few complications to my recruitment method while approaching the other organisations, however. Because it is based in Tāmaki Makaurau/Auckland, AAAP's meeting spaces and actions were not readily accessible to me in Te Whanganui-ā-tara/Wellington, nor were its organisers accessible for kanohi ki te kanohi. As a result, I used social media to make the initial contact, through which I successfully recruited the organisation's 'coordinator' who oversees its digital media, communications and press training. ${ }^{17}$ This approach worked in part because AAAP's coordinator and I have a mutual colleague ${ }^{18}$ who assured me that they would be highly

\footnotetext{
my exposure to them through participation in local social movements; another aspect of tikanga features valuing knowledge of one's whakapapa (O'Carroll, 2013, p. 36).

${ }^{12}$ Face-to-face interaction.

${ }^{13}$ Family.

${ }^{14}$ Purpose, programme, theme.

15 Physical presence.

16 To preserve confidentiality, I refer to each research participant using singular they/them pronouns.

${ }^{17}$ AAAP's coordinator role is also the only paid one in the organisation.

${ }^{18}$ With whom I am acquianted in a face-to-face capacity.
} 
approachable, and in part because I introduced myself as a member of PAPA, with which they were already acquainted.

For PAPA, I noted that my pre-existing relationship to and familiarity with the organisation and its members posed the risk of developing cognitive biases that might affect the interview and analysis processes. To mitigate these concerns and ensure the validity of the organisation's participation, I selected a participant who was not based in the Te Whanganui-a-Tara/Wellington branch with me. Because I had a greater geographical and therefore social distance from this member, I ensured that our interview would be more formal than interactions with them in a strictly PAPA capacity would be. This participant was PAPA's 'national research coordinator', whose role involves the dissemination of the organisation's research work through its media channels and thus heavy involvement in the organisation's press and social media. We successfully arranged a face-toface interview that coincided with one of their trips to Te Whanganui-a-tara/Wellington during my field work period.

\section{Interviews}

I obtained human ethics approval for this research on 16 November 2018 after ensuring that I would obtain two levels of consent from each interview participant. For the first, interviewees signed informed consent forms to participate as individuals. Then, because interviewees would be speaking on behalf of participating organisations, a second level of organisational consent had to be attained. This took the form of signatures from two members of an authoritative body within each organisation. Of the six organisational signatures I then obtained, two were from Māori (though none of the interview participants were Māori, given that the priority for this research was to recruit participants based on the media-related work that they do for their respective organisations).

From there, my commitment to tikanga also informed the data collection process by ensuring that all initial interviews were conducted kanohi ki te kanohi. For UW and PAPA, it ended up being possible to conduct face-to-face interviews in Te Whanganui-a-Tara/Wellington, where I 
was based, but I travelled to Tāmaki Makaurau/Auckland to afford the same treatment to AAAP. Upon meeting, I conducted semi-structured interviews with each participant. The flexibility afforded by this structure enabled us to develop a better understanding of their approaches to movementbuilding by guiding our conversation in that direction, but by also allowing room for expansion on unforeseen lines of thinking. Questions loosely mapped across different stages of the political activation process established in the literature by asking how the participants imagine their target audiences; how participants produce and distribute their media to get audiences' attention; how participants motivate their audiences to care about their issues; how participants persuade audiences that they have the capacity to act on those issues; and what obstacles interviewees encounter in carrying out this work (see Appendix for the complete interview schedule). Furthermore, I also asked UW and AAAP's participants additional questions regarding their organisations' respective backgrounds to counterbalance my existing familiarity with PAPA's organisational history. In total, I conducted three of these initial interviews and obtained consent from each participant to record them. I conducted follow-up interviews with participants based on clarifying questions I generated during the data analysis process. Follow-up interviews were also conducted kanohi ki te kanohi in order to maintain rapport and continue to demonstrate my commitment to the participants even after the bulk of their contributions had already been made. I conducted one follow-up interview with the AAAP participant and two follow-up interviews with the participant from PAPA, and none with UW (my analysis of UW's data generated no further questions). Upon completion, I transcribed all interview recordings in Microsoft Word and formatted them with line and page numbers in preparation for data analysis. Only one participant requested a transcript copy. 


\section{Data analysis}

Before beginning data analysis, I took additional precautions to ensure that I could adequately "bracket" my longer involvement with PAPA compared to the other participating organisations. Bracketing in qualitative research involves mitigating the "potentially deleterious effects of preconceptions that may taint the research process" (Tufford \& Newman, 2010, p. 80). While drawing on my previous organising experiences helped with developing a method for recruitment, as described above, doing so for data analysis ran a much higher risk of producing an analysis informed more by PAPA than the other organisations in the sample. To address these concerns, I gradually withdrew from all of my roles in PAPA by the time I finished data collection, which helped to prevent a continued involvement with the organisation from superseding my involvement with UW and AAAP. Furthermore, as described previously, I made active contributions to each participating organisation during the field work period to demonstrate my commitment to each in accordance with kanohi kitea. ${ }^{19}$ Though I intended these contributions to assist in the recruitment process, they also ensured that I spent a similar amount of time working with each organisation in the months leading up data analysis. As a result, I was better able to "render audible the nuances and subtleties of [every] participants' responses" (p. 91) by ensuring that my recent experiences in the field were equally informed by each organisation.

After taking these steps to bracket my prior involvement with PAPA, I then conducted a thematic analysis on the data collected from the interviews, which involves identifying, organising and reporting on patterns of meaning within qualitative datasets. Virginia Braun and Victoria Clarke (2013) consider thematic analysis to be a flexible method with a wide range of uses in the social sciences that does not sacrifice richness of detail in the process. They identify seven stages to the

\footnotetext{
${ }^{19}$ In AAAP's case, because it has no presence in Pōneke/Wellington, I coordinated with the organisation's coordinator and PAPA's Tämaki Makaurau/Auckland branch to start figuring out ways that the organisations could start to collaborate more closely. These efforts included plans for representatives of PAPA's local branch to attend AAAP meetings in person. Though this planning took place after my initial interview with AAAP's coordinator, I did so to ensure that I had made some sort of tangible contribution to each participating organisation.
} 
method, which I ultimately followed: (1) transcribing the interviews to produce a dataset; (2) familiarising oneself with the data; (3) generating initial codes; (4) searching for themes; (5) reviewing themes; (6) defining and naming themes; and (7) producing the report (pp. 202-203). Braun and Clarke also stress the active role researchers play in identifying themes; they argue that themes do not "emerge" from the data but are constructed by the analyst (p. 225). This distinction allows the researcher to better reflect the theoretical framework(s) applied to the data.

During the data familiarisation stage, I read through each transcript twice - once to get a grasp of the data and to take notes where ideas appeared similar or recurrent, and a second time to then apply some of those ideas back across the earlier transcripts where I missed them initially. Some of these notes eventually evolved into codes. During the code generation stage, I used complete rather than selective coding, which involves coding anything within the data relevant to my research questions as opposed to selecting specific 'instances' of relevant phenomena (Braun \& Clark, 2013, pp. 206-7). Furthermore, my codes took on both semantic and latent forms: semantic codes speak to what is literally in the data, while latent codes identify the more implicit ideas contained therein. This more holistic approach to the coding process proved necessary to actualise the potential for "rich data" promised by thematic analysis (p. 206).

I generally used semantic codes to cover straightforward responses to the interview questions. For example, some participants explicitly described the stages of their social media production cycle, delineating between different platforms, messaging and content structures to explain how they thought those factors inform political activation. These points were all literally present in the data. Latent codes only became apparent upon analysis through a lens provided by my theoretical framework or its related literature, such as when participants spoke of their relationships to other social movements. In this case, I recognised that these data exemplified NSM traits and those of social movements more generally in networked societies as highlighted by Lievrouw (2011) and Castells (2012), respectively. I also coded data that had even more peripheral 
relations to the research questions. For example, each participant confirmed their continued use of traditional media (i.e., print and broadcast news) in addition to digital media, which I coded in order to produce insights from those juxtapositions which might further clarify their specific roles in political activation.

Once I coded the data, I then collated the codes from all datasets and began sorting them into categories based on association with concepts from the literature or which spoke to the research questions directly. These were not themselves themes; they had a categorical rather than thematically resonant relationship. For example, "women", "transgender" and "Māori" were all demographic features that came up in discussions about outreach, and were therefore sorted into a category titled "demographics" which encompossed codes related to the specifics of participants' media audiences.

With the data coded, collated and organised, I then began to construct potential themes. To assist the theme construction stage, I opted to further contextualise the interview data by supplementing them with publicly available media texts produced by the participating organisations. These texts included social media posts, press releases, academic journal articles and books produced by the organisations, as well as news articles and videos covering them and digital resources designed by them for members of their respective bases. Collecting these supplements helped verify claims made by interviewees about their media practices; such texts either covered events we discussed or were themselves the subject of our discussion. Many of these texts (primarily news and social media) are also included in the findings chapter as key examples of the concepts and strategies elaborated on during interviews, while others (primarily academic journal articles and books) offer additional theory, context and rationale for those concepts and strategies.

These supplements ultimately informed the final set of themes, which detail three theoretical objects around which the participants described building their strategies for facilitating political activation. The first theme concerns the affordances of the tools participants use to acquire 
the attention of their audiences; the second theme examines the conflicts with oppositional actors and institutions that restrict (but sometimes enable) pariticipants' media activity; and the third theme considers how the participating organisations leveraged overlaps between the values and goals of their own movements with others in their networks to motivate cross-movement mobilisation. The next chapter will explore these themes in greater detail. 


\section{Findings}

I conducted face-to-face interviews with three media-oriented organisers from People Against Prisons Aotearoa (PAPA), Auckland Action Against Poverty (AAAP) and Unions Wellington (UW) between the months of December 2018 and February 2019. As described in the previous chapter, I then conducted a thematic analysis of the interview transcripts and supplementary media texts produced by or featuring the participating organisations. The analysis focused on how participants use media technologies ranging from traditional news broadcasts to networks on social media platforms to acquire the attention of their target audiences, as well as how participants then build on this attention to facilitate their audiences' political activation.

This chapter covers the findings from that analysis, which are organised into three themes that describe how participants' strategies for engendering greater participation in their movements are enabled and/or constrained by technological, social, cultural and political factors. Those themes include 1) the affordances of the media platforms, news outlets and communication techniques used by participants to facilitate the acquisition of attention and political activation; 2) the conflicts between SMOs and their oppositional actors, in which the latter tries to suppress or discredit the media activities of the former that highlight ways of participating in their struggles; and 3) the opportunities to motivate cross-movement participation enabled by participants' identification of overlaps between their own movements and those of others in their networks. The themes are broken down further by organisation, a level of granularity that demonstrates how participants' strategies for using media to facilitate political activation are heavily informed by their sociopolitical contexts. 


\section{Affordances}

One of the most notable aspects of participants' descriptions of their movement-building strategies was how they identified and capitalised upon the affordances of various social media platforms, news outlets and other means/modes of communication to acquire the attention of specific audiences. As described in the literature review, affordances in this sense "enable (and also constrain) ... the conditions of possibility associated with an action" (Hutchby, 2014, p. 87). The affordances of media technologies and other means of communication informed what each participant's organisation found it could and could not achieve through those tools. Participants universally described their overall media strategies as multiplatform, but how they use those platforms varies according to their organisations' respective sociopolitical contexts.

\section{Affordances - UW}

When discussing the role of media in their organisation's strategies for building the union movement, my interviewee from UW emphasised the organisation's social media use more than any other participant. Although their description of the organisation's media strategy also included news coverage, most of the interview revolved around how the organisation uses Facebook to build its base. UW found Facebook's affordances for sharing tonally diverse content across a demographically (and even geographically) diverse network appealing for its movement-building activities. However, as the local affiliate council for unions in the Te Whanganui-a-Tara/Wellington region, UW's interviewee explained how the organisation must ultimately answer to those member unions whose strategic priorities do not always include media visibility:

UW interviewee: I think the media [are] quite important. In some ways there's a lot of stuff going on on the internet, but the union has a finite amount of resources so part of that is built around the immediate task - collective agreements and representing members - and that's where the focus is. Having a more abstracted political perspective, thinking and the bigger picture stuff, unions still do it, but [media visibility] comes secondary... 
Since the organisation is funded by those unions and must ultimately defer to them in a formal sense, any media work that UW seeks to do needs to have as little impact on its resources as possible. These constraints have resulted in a strategy that makes heavy use of Facebook, given the low cost of their use. UW's interviewee identified affordances of Facebook's features which 1) enable the organisation to capture and maintain the attention of its target audiences through strategic use of knowledge of Facebook's algorithms by tailoring content to specific audiences and retaining a presence on those audience's content feeds, and 2) facilitate those audiences' political activation in part by presenting opportunities to build their audiences' capacity to participate through content that models what participation in the union movement can look like.

The first feature we discussed is the "Insights" tab available through Facebook's page management tools, which provides data to page administrators ranging from the number of views of a Facebook page over time to the gender and age demographics of that page's audience. Through the Insights feature, UW gleans information about its audience that goes on to inform the types of content the organisation shares:

UW interviewee: If you look at our Facebook stats it tends to be broadly young, but not like teenagers, more 24-25 [viewing our content]. Because it's been mostly responding to issues, like the café stuff with Five Boroughs, there has been a huge engagement with much younger people in the hospitality industry. When we've done stuff supporting the PSA (Public Service Association) or the public transport stuff or the teacher's strike and doing videos like that, then that stuff tends to go out through those networks, which means that we think about the demographics of those working bodies.

From the information provided by the Insights feature, UW knows that a majority of its audience on the platform are young adults, who are statistically "far less likely to become members of political or civic organizations such as parties or trade unions" (Loader et al., 2014, p. 145). Consequently, the organisation has opted to distribute content on the platform that is more informal and even humorous. This approach corroborates research that has previously suggested these communicative modes are more appealing to young people (Sørensen, 2016; Bode \& Becker, 2018, p. 1574), and therefore yields greater communicative affordances for acquiring the attention of that group. 
Another key feature of Facebook that UW uses is the "Share" button, which enables the easy redistribution of already-made content. This sharing feature is especially valuable to UW given how limited its resources are for doing media-related work when the organisation's constituent unions do not prioritise such strategies; sharing existing content means the organisation does not have to spend time and energy producing new content. Even when that content does not need to be produced, however, UW's interviewee found that sharing that content consistently with the organisation's audience is constrained by Facebook's algorithm. The interviewee described this algorithm as "a weird sort of beast" that makes it difficult to predict how many people a post will reach. To navigate such constraints, UW's interviewee described dividing the [mostly] redistributed content it shares into two categories: "fluff", or informal and humorous content, and more "serious" content from news outlets and other sources that the organisation uses to articulate its positions on current events, as well as subsequent calls to action. Fluff content generally takes the form of internet memes that relate to union politics in some way (see Figure 1), which UW's interviewee explained are selected based on criteria related to how entertaining and accessible their messages are:

UW interviewee: I think the idea and the hope and the target is that this regular fluff material might be funny or might be easy to understand. The hope is that the fluff keeps [UW] in the algorithm and the serious stuff still gets around to some extent... It's noticeable that the fluff content has much better [engagement] metrics than the non-fluff...

As this excerpt demonstrates, UW believes the accessibility of fluff content helps the organisation manipulate Facebook's algorithms in order to more consistently reach its audiences and acquire their attention. When exposed to content like that in Figure 1, Facebook users then have the capacity to interact with it using simple features like the "like", "comment" and/or "share" buttons located underneath each post. UW's interviewee described this kind of activity as "feeding" the algorithm by providing it data that suggests those users are interested in union-related content, which then delivers that content to those users more often. In other words, they believed that the 
more users interact with the organisation's Facebook posts, the more the platform's algorithms deliver UW's content to users' news feeds and retain their attention. ${ }^{20}$



Figure 1: UW shares a meme on Facebook, posted 20 July 2019. Image captured 2 August 2019.

UW's interviewee believed that by building up a following based on fluff first, the organisation could then direct that following's attention toward more serious content that could more explicitly facilitate political activation through consideration of how to build the capacity for

\footnotetext{
${ }^{20}$ To help expose the organisation's desired audiences to its Facebook page's content, UW's interviewee also mentioned in passing that union delegates who visit workplaces in person to help organise them often "link up" with workers through Facebook during that organising process.
} 
participation, or the ability to participate and know that doing so matters (Bode \& Becker, 2018, p. 1575). The most common form of serious content features the organisation regularly sharing news articles on its Facebook page anywhere from once a week to several times daily. These articles typically cover some form of industrial dispute of local, national or international scope. The organisation utilises Facebook's posting feature to position its commentary next to the headline and thumbnail image of an article covering the dispute (see Figure 2). The included commentary typically features quotes from unionists and members of the public who comprise the pro-union aspects of the coverage in the news article. The more local iterations of this form of "serious" content also involve informing UW's Facebook audience of political activities that its members can get involved in, such as strike pickets and public meetings.

"Wearing stickers was just a cute way for members to support one another. H\&Ms reaction to send members home is so out of proportion. We aren't going to be intimidated though, we are going to stick together and look after each other," H\&M employee Anaise Lenati says.



TVNZ.CO.NZ

Auckland H\&M workers suspended after sticker protest for living wage

(1):99 
In our interview, UW's interviewee emphasised that localised serious content is ultimately designed to highlight pathways for offline involvement in the union movement-in their words, "to use online stuff to engage in offline stuff". Through serious content, UW's interviewee seemed less concerned about articulating the organisation's politics through media than they were about showing what participation in the movement looked like, which the interviewee based on an assumption that "a majority of [all] people actually support working-class politics" already. While not as "funny" or "easy to understand" as the union memes UW's page also shares, the organisation structures this more topical content to benefit from (rather than feed) Facebook's algorithms. In other words, serious content is as likely to appear on UW's followers feeds as fluff because it comes from the same source. The organisation's interviewee believed that this strategy enables the organisation to model to its audience what participation in the union movement looks like on a local scale, raising the participatory capacity of its audiences by showcasing how to do so through coverage of the struggles of local workers.

Though UW's interviewee emphasised its social media use during our interview, we still discussed the organisation's news media strategy once prompted. UW's interviewee ascribed significant value to the "media power or narrative power" that news media afford when enough attention is acquired on an issue. They thought that "massive multinational companies" involved in industrial disputes appeared vulnerable to "ambitious narratives of people fighting back", but conceded that UW only contributes to those media narratives in highly specific instances. In terms of news media, UW is a peripheral body to unions themselves, and because of that it only gets involved in the news for situations where a union is not going to get directly involved despite workers' issues still being at stake. The example the organisation's interviewee gave featured a local restaurant that received negative news coverage for alleged wage theft (Winter, 2018b). The restaurant's workers were not unionised, and news coverage indicated that no solution was in sight. Without a union official for the journalist covering the story to refer to, UW stepped in to provide statements on the illegality of the employers' actions (Winter, 2018a; 2018b). The organisation attributed its 
involvement to a $\$ 35,000$ payout eventually delivered to the affected workers as compensation for their withheld leave entitlements (Winter, 2018a). In this way, UW builds up its own visibility through involvement in existing news narratives that would have otherwise had no union presence, using the news media's affordance of "narrative power" to build the organisation's visibility while advancing workers' interests in situations where unions do not.

As a [self-described] more "flexible" branch of the union movement than the unions themselves, UW has opted to focus on movement-building activities beyond actual unions' more "immediate" administrative tasks of "[negotiating] collective agreements and representing members". The organisation's media strategies - between sharing pre-made memes to gaming Facebook's algorithms and communicating more serious discourses and calls to action to wider audiences - are heavily informed by the affordances of the platform and outlets it uses. While fluff content helps UW navigate the attention economy by ensuring that the organisation is visible to its followers on Facebook and therefore capable of acquiring their attention, the more localised "serious" content ensures that the capacity prerequisite for political activation is addressed to some extent by showing what people can do to advance union politics.

\section{Affordances - PAPA}

My interview with PAPA produced the most balanced emphasis on social and traditional media of all three participants. While UW's interviewee assumed audiences' existing familiarity with and/or support for its union-based politics, PAPA's interviewee emphasised strategies they have had to adopt to improve both the visibility of the organisation and of prison abolition politics in general. The organisation's interviewee demonstrated awareness of how media technologies both enabled and constrained those goals, with a more critical eye toward those constraints than the other participants.

PAPA's interviewee stated that the organisation's use of social media is "fundamental" to making its politics known and visible to people outside of prison, "even if it doesn't get you all the 
way". This appraisal is primarily due to how social media afford the organisation's visibility to its followers on regular basis through a consistent - if not always daily - stream of content. The organisation's interviewee stressed how they post two to three times a day on its Facebook and Twitter accounts so its online following is exposed to prison abolition-related content as much as possible. Unlike UW, however, which delineates between "fluffy" and "serious" content, PAPA's content largely resembles the latter. The organisation's interviewee described its serious content as "reckons", which constitute reinterpretations of criminal justice-related news narratives through a prison abolitionist lens (see Figures 3 and 4). Much like UW, these news-based posts typically include a link to an online news article and are accompanied by commentary that reframes the story through the lens of the organisation's politics. Rather than using quotes from the article that are supportive of that frame, as UW can, PAPA often has to take an extra step in its commentary to produce an abolitionist reckon. For example, Figures 3 and 4 showcase PAPA's posts on Twitter and Facebook, which both share an article by Newshub about a study that found prisons do not prevent violent crime (Satherley, 2019). The article does not include any perspectives that argue explicitly for prison abolition, a gap that PAPA fills in its own words through Facebook's and Twitter's posting features. 
Prisons are not effective at either rehabilitating or deterring perpetrators of social harm. To do both, we must go beyond the prison system.

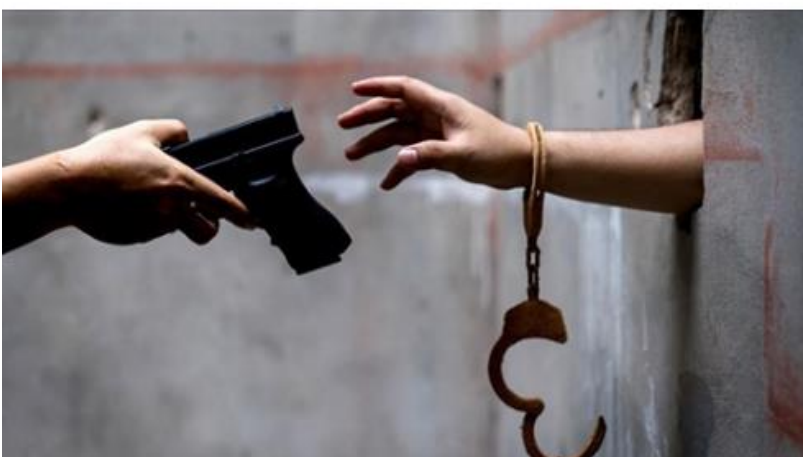

NEWSHUB.CO.NZ

Prison does almost nothing to stop violent crime - study Sentences don't deter criminals and keeping them behind bars has little

(1): 100

6 comments 30 shares

$\Rightarrow$ Share
Figure 3: Example of PAPA's 'reckons' on Facebook, posted 15 May 2019. Image captured 13 June 2019.
People Against Prisons Aotearoa

@againstprisons

Prisons are not effective at either rehabilitating or deterring perpetrators of social harm. To do both, we must go beyond the prison system.

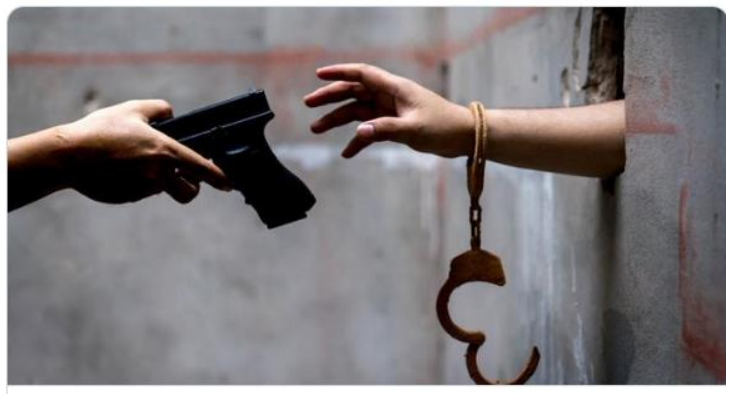

Prison does almost nothing to stop violent crime - study | Newshub Sentences don't deter criminals and keeping them behind bars has little effect on crime rates.

o newshub.co.nz

11:00 AM - May 16, 2019 - TweetDeck

23 Retweets $\mathbf{4 3}$ Likes

Figure 4: Example of PAPA's 'reckons' on Twitter, posted 16 May 2019. Image captured 5 Aug 2019.

Another key affordance PAPA's interviewee identified in the social media platforms the

organisation uses is the mobilisation facilitated by Facebook's event pages. They described the event

page feature as essential to mobilising the people already within the organisation's networks:

PAPA

interviewee:

You're relying on interpersonal social networks both online and in person in order to grow them. I mean, Facebook events are really fundamental. There is no way in which we would be able to organise the current things we are organising without Facebook events.

Event pages include their own set of features, such as an RSVP button and notification reminders when an event is upcoming. Such features help the event organisers to prepare for the scale of the turnout of an action, while the notification reminders ensure that more people remember to attend. ${ }^{21}$ However, PAPA's interviewee expressed concern that the reach of the organisation's Facebook event pages might be constrained by the platform's content algorithms through a 'bubble effect' like that theorised by Pariser (2011). As UW also observed, these algorithms extract data from

\footnotetext{
${ }^{21}$ While only PAPA's interviewee discussed its use of Facebook events explicitly, the other participating organisations' Facebook pages show that they too use the feature for mobilisation.
} 
users based on their expressed interests and then prioritised content for those users which aligns with those interest. Despite PAPA's Facebook event pages being public (anyone can see them, regardless of whether they follow the organisation Facebook), the organisation's interviewee worried that algorithms limited the organisation's ability to extend its reach beyond its existing base of members and supporters when communicating messages or facilitating mobilisation through social media.

To strategise around these shortcomings to acquiring attention through social media, PAPA's interviewee described how the organisation designs its actions and news media to themselves generate attention toward the organisation that can then be directed at its next event or story:

PAPA Our reach is limited by the bubble effect on Twitter and Facebook. But what interviewee: happens is when we do an action, or a particularly effective press release or report, we burst that bubble and reach more people, and that's how people can understand us in an exceptional way.

PAPA's interviewee expanded on these exceptional moments, explaining that they "unofficially" signal to the organisation's existing audience that the issue at hand is important enough to warrant wider attention. At this point, the organisation's audience members allegedly respond by utilising Facebook's features to share that content with their own networks. Though PAPA's interviewee was unable to identify what catalyses these moments, they did speak to how one of the ways it sends the aforementioned signal is through press conferences. These conferences tell "an entire story [to the news media] by presenting both a problem and a solution", though PAPA's interviewee believed this tactic can "only be used in exceptional circumstances". Such "bubble-bursting" moments are an important part of the organisation's strategy for acquiring more attention from the general public and growing its audience.

As such, PAPA's interviewee found news media to afford significant access to public attention; indeed, when beginning to describe the organisation's strategy for attracting news media, they explicitly stated that "part of the point is that we need to get [people's] attention." However, they also perceived the general public's disapproval of the organisation's more radical ideas to be 
another obstacle to acquiring that attention. The interviewee expressed the belief that prison abolition is currently an unpopular topic in New Zealand's media environment, and that abolitionist politics have difficulty gaining traction outside of prisons themselves as a result. The organisation's interviewee argued that this sociopolitical context is so constraining that offline, unmediated means of communication are more effective at convincing people of the "correctness" of PAPA's politics. When I asked what the most important factor was to the organisation's facilitation of political activation in its target audiences, PAPA's interviewee strongly emphasised the unique affordances of face-to-face engagement:

PAPA participant: I really think it's the face-to-face. I think at this point, it requires someone to just sit there and explain to you, or just have that conversation with you, and just have that compassionate discourse that's not really possible online. I've been able to recruit strangers to the organisation who could've seen us on social media, or known about who we were, but it wasn't until someone just sat them down and talked with them about how important our kaupapa is that they were able to fully buy into it.

What this response suggests is that, while media are seen by both the research participants and the literature to play a fundamental role in SMO outreach activity (Lievrouw, 2011; Cammaerts et al., 2013) and thus political activation, the distinctions between the affordances of mediated and unmediated means of communication are much starker for PAPA. The organisation finds that communicating face-to-face with people outside of the prison abolition movement affords a degree of personal investment in the movement's politics that is not possible solely through PAPA's news media appearances, social media content or any other media the organisation produces.

These sociopolitical constraints to PAPA's ability to acquire its desired audiences' attention are even more apparent in traditional news media. PAPA's interviewee explained that the organisation has to carefully consider how it frames its actions and politics in order to be broadcast at all. In order to utilise the affordances of the medium, which PAPA's interviewee understood to include acquiring the attention of audiences and oppositional actors alike, the organisation requires its spokespeople to tone down the language they use while ultimately conveying the same ideas: 

interviewee: $\quad$ abolitionist ideas, we sometimes have to talk about things in a way which is either coded, or in a way which speaks to people about abolitionist ideas without using the words 'prison abolition', or using words which will scare people away.

By presenting its more challenging claims about prisons less directly, PAPA is able to ameliorate hostile reactions to its politics from both journalists and audiences. ${ }^{22}$ The organisation's interviewee cited the rhetoric in its campaign to end solitary confinement as a key example of this tactic. Though PAPA understands the end of solitary confinement to be a key "stepping stone" toward prison abolition (Lamusse et al., 2016, p. 63), the organisation's interviewee did not talk about its solitary confinement campaign in these terms. Instead, they emphasised more palatable arguments to the journalists and audiences the organisation wanted to reach. In a 2018 press release issued by the organisation, PAPA frames the practice of solitary confinement in New Zealand prisons as a violation of international law and human rights ${ }^{23}$ (2018a), calling for its abolition in a way the organisation hopes will still appeal to audiences who are not already on board with prison abolition more generally. As the excerpt above stresses, this issue framing gets the organisation's "foot in the door" to talk about abolitionist ideas while still refusing to compromise the movement's goals by entrenching some other aspect of the criminal justice system (e.g., by solving prison overcrowding through the construction of more prisons). Only once these conditions are met can the organisation utilise the affordances of news media.

One of the most important affordances PAPA sees in traditional news media is its ability to reach incarcerated audiences. This affordance is crucial for PAPA because according to its interviewee, most people in New Zealand prisons cannot access social media. Regardless of how the organisation frames its actual messages, however, PAPA still needs to make those messages visible

\footnotetext{
${ }^{22}$ This framing tactic resembles the larger strategy exhibited by the union publications featured in Taylor and Grey's (2014) case study, which "ceased articulating any structural analysis to their constituencies" out of reaction to the hostility of such analysis by the state and market (p. 82).

${ }^{23}$ Note that human rights discourses are commonly used by NSMs.
} 
to a mass audience, which requires the organisation to put effort into being "unignorable" on its own merits:

PAPA We'll do an action, maybe something confrontational, maybe something interviewee: $\quad$ illegal, never anything violent, but like a protest or a rally or an occupation or a picket or something like that which is hard for the media to ignore, and it's hard for the government to ignore, right? In that instance, we are forcing ourselves into the media by basically being unignorable.

Cammaerts et al. (2013) suggest that vying for visibility in this way is essential to "the achievement of public recognition and for the exposure of activists' causes and social movement frames" (p. 10). PAPA prioritises that recognition more than UW not only because it affords access to prisoners, but also because the prison abolition movement does not have nearly as many SMOs or unions contributing to it in Aotearoa/New Zealand as the union movement does-as evidenced by how PAPA refers primarily to overseas abolitionist organisations in its published works (e.g., "No Pride in Prisons on Abolitionist Politics", 2017, p. 132). Without such support, PAPA is obligated to exploit every affordance it can find in news media for its audiences both inside and outside prisons.

One of the most important aspects of PAPA's ability to attain traditional news coverage that we discussed is how its members build relationships with individual journalists, without whom these affordances are not accessible. The organisation's interviewee argued that one of the biggest challenges to achieving news coverage is how constrained journalists are by their working conditions in their ability to verify sources for whatever issue PAPA is trying to draw attention to:

PAPA In terms of the media itself, the biggest obstacle that we face is the way in interviewee: $\quad$ which particularly private media is structured so that there is very little ability for everyday journalists to go away and check that what we are saying is correct. We know what we're saying is correct, but the journalists don't necessarily have the confidence with an organisation that they don't necessarily know very well to then republish the stats that we give to them, right? 
Because of these constraints - both in terms of journalists' working conditions and a lack of organisational history to draw on or have a relationship to ${ }^{24}$ - the organisation's stories are often not picked up. To prevent this from happening, the organisation's interviewee explained that it now attempts to build relationships with journalists by facilitating their fact-checking processes, which involves providing journalists with facts and sources related to a story in an "under the table" capacity. Framing this data as an exclusive scoop for journalists is a tactic designed to facilitate source verification and increase the likelihood that a story will be published. Taken together, this strategy builds relationships with journalists while ameliorating some of the constraints to their working conditions, which better positions the organisation to attain some degree of legitimacy (Koopmans, 2004) in its news coverage.

PAPA's interviewee also looked at how news outlets outside the mainstream, particularly Māori media, afford more targeted audiences but can still reach prisoners. They stated that there is "a consistent effort on [PAPA's] part to reach Māori and Pacific working-class people", for whom prisons are an even more significant issue. Though the organisation cites statistics of Māori and Pacific incarceration rates often (Lamusse et al., 2016, p. 2), PAPA's interviewee also shared more "anecdotal" evidence that there is a large audience for Māori media inside prisons. To capitalise on how Māori media afford access to a niche audience of importance to PAPA, the organisation tailors its news strategy to those media by fronting a Māori spokesperson and appealing to journalists for Māori Television programmes like Te Kaea, an evening news programme, as well as on radio through Māori outlets like Radio Waatea. PAPA has found that because Māori media outlets are particularly interested in prison issues, the organisation ends up having an easier time attaining coverage through those outlets.

\footnotetext{
${ }^{24}$ PAPA has only existed in some form or another for four years as of writing, and half that time under a different name.
} 
PAPA's interviewee demonstrated an awareness of its media outlets/platforms' affordances that spoke both to their general use for social movements and to the organisation's specific sociopolitical context. The features enabling these affordances included Facebook event pages that facilitated mobilisation through RSVP and reminder features, to news media that could actually reach prisoners themselves. However, the organisation's interviewee also considered at length what these media technologies did not afford, given how they confined critical discourse on New Zealand's criminal justice system to audiences that were already at least nominally supportive of PAPA. To account for this, we discussed how the organisation now exploits the affordances enabled by face-to-face conversations, as well as how much more easily the organisation can earn coverage through Māori news outlets. Such a strategy highlights how the organisation's multiplatform approach to acquiring attention and facilitating political activation enables it to take action or communicate in ways that are more restricted in some technologies and communicative modes than others.

Affordances $-A A A P$

AAAP's coordinator emphasised traditional news media outlets over social media to the extent that the latter only came up when prompted. They rationalised this preference based on the belief that traditional news media afford larger audiences:

AAAP The one thing we do do a lot is using traditional media, in forms of news interviewee: outlets, as a platform for propaganda around the ideas we want to push through our spokespeople and media releases. That's a really useful tool we have at our disposal to ensure that we kinda wedge ourselves in the narratives on welfare, to get our own specific message out there, which hopefully connects with a large number of people because of the audience those outlets have.

Like PAPA, AAAP seeks to access the mass audience afforded by traditional news media in order to draw attention to its politics on a national scale. Unlike PAPA, however, which has to draw attention to and justify the very idea of prison abolition, AAAP seeks to influence existing welfare narratives by leverage of being present in them whenever possible. The organisation's key strategy for achieving 
this presence revolves around having a diverse pool of spokespeople who fall into one of two categories: some are "representatives of the organisation", while the others are simply "affected by the issues", and therefore able to speak from a more personal perspective than the more policyoriented messages put forth by the organisation itself (Auckland Action Against Poverty, 2019c). ${ }^{25}$ In an example of how the organisation deploys these two spokespeople categories, a news story run by the news programme Checkpoint in early July 2019 highlights how beneficiaries in the South Auckland district Manurewa formed a queue outside their local Work and Income office in the early hours of the morning (Blake-Persen, 2019). In Checkpoint's coverage, people in the queue itself share personal stories highlighting the desperate nature of their situation, while AAAP's representative speaks to the bigger picture, such as policy-oriented reasons for that desperation. The organisation's interviewee found this two-pronged approach highly effective at drawing attention to both personal experiences and more "radical" political stances in public welfare discourses.

AAAP's interviewee believed that its media strategy's emphasis on personal experiences not only affords the organisation's politics a more visible position in news discourses around welfare, but also better "resonates" with the audiences AAAP specifically wants to reach:
AAAP
I think it's quite powerful in the media work that we do that the political interviewee: messages are coming from the people who are actually having those lived experiences, and that kind of does help resonate (emphasis mine) with the people we're working with because ultimately, they see themselves represented in the media.

The emphasis in this excerpt on the visibility, resonance and [implied] legitimacy of spokespeople's narratives echo Koopmans' (2004) three selection mechanisms for the public sphere. However, while Koopmans argues that resonance and legitimacy hinge on reactions from "other actors in the public sphere" like journalists and pundits (p. 374), AAAP's interviewee expressed much more interest in

\footnotetext{
${ }^{25}$ AAAP's interviewee noted in the follow-up interview that these categories are not mutually exclusive; in fact, the organisation's official spokesperson in the example following this footnote, Kathleen Paraha, is herself a beneficiary and began her involvement in AAAP by participating in a news story from the Work and Income office queues.
} 
resonating with the audiences of the organisation's media appearances. Because spotlighting beneficiaries' individual plights in the news ensures that their cases "get sorted by the Ministry [of Social Development] quite quickly", AAAP believes it can demonstrate to its audiences that "speaking out in the media" can help beneficiaries receive their entitlements and push for "systemic" change. In addressing how and why audiences should engage with AAAP and its politics, the organisation's interviewee argued that this strategy addresses both capacity and motivational prerequisites for political activation.

However, AAAP's interviewee demonstrated awareness that the organisation's politics are potentially off-putting to audiences. The interviewee described AAAP as "the sharp end of the arrow" in the wider scope of the country's anti-poverty movement, but in doing so conceded that "it does become more difficult for us sometimes to get people on board when we're pushing for the further [left], more radical ideas." While PAPA's interviewee described how their organisation approaches news media by toning down the political language they use, however, AAAP strategically includes non-members in its media narratives to ensure that their personal stories are seen as congruous with the organisation's politics. To prepare these people to speak to journalists, AAAP's interviewee described how the organisation helps them construct what they feel they need to say in ways that best suit the news format. This preparation takes factors into consideration like whether they are participating in a pre-recorded interview (in which the questions might be knowable in advance) or a live interview (in which those questions would need to be anticipated and interjections practiced). Each of these formats has its own respective communicative affordances; pre-recorded interviews enable spokespeople to prepare more articulate statements, while live interviews are comparatively more off-the-cuff and therefore generate more "authentic" responses. By training beneficiaries outside of the organisation to participate in these processes alongside AAAP's official spokespeople, the organisation "sutures" (Funke et al., 2012) that particular workingclass experience to a radical public welfare narrative. This strategy not only makes that narrative more relevant, but increases the capacity for political activation in the beneficiaries participating in 
the process by helping them learn the skills necessary to participate in political discourses in the news media.

One of the only exceptions to AAAP's overall strategy to involve its base in its media production is the organisation's approach to media releases, which the organisation's interviewee thought afforded an avenue for enhancing its visibility in both traditional and social media simultaneously. Media releases enable the organisation to articulate its positions and demands in full-if not through a traditional news platform, then a news-adjacent one that can be distributed just as easily to news outlets as it can be shared on social media platforms (see Figure 5). News outlets can select quotes from releases to include in their own coverage, while sharing releases on social media affords AAAP a longer-form format than Twitter's character limit or Facebook's "read more" hideaway feature allow. This cross-posting strategy therefore combines the affordances of each medium through a single content form that is universally compatible, exemplifying the organisation's multiplatform approach to acquiring the attention of its desired audiences. ${ }^{26}$

\footnotetext{
${ }^{26}$ This strategy not used frequently, however; upon examination of the organisation's Facebook page, only one post in 2019 linked to a media release from the organisation (see Figure 5; Auckland Action Against Poverty, 2019a).
} 
We're starting the year by calling for a substantial increase in baseline benefit levels. The latest report by MSD shows that more people than ever are living with incomes that are not enough to cover food, rent, and other basic expenses. For the first time in over 5 years food grants make the largest proportion of the total of amount of hardship grants.

We will continue advocating for people at Work and Income and campaigning for a welfare system that allows people to live with dignity.

Help us kickstart our 2019 stronger than ever:

www.aaap.org.nz/donate

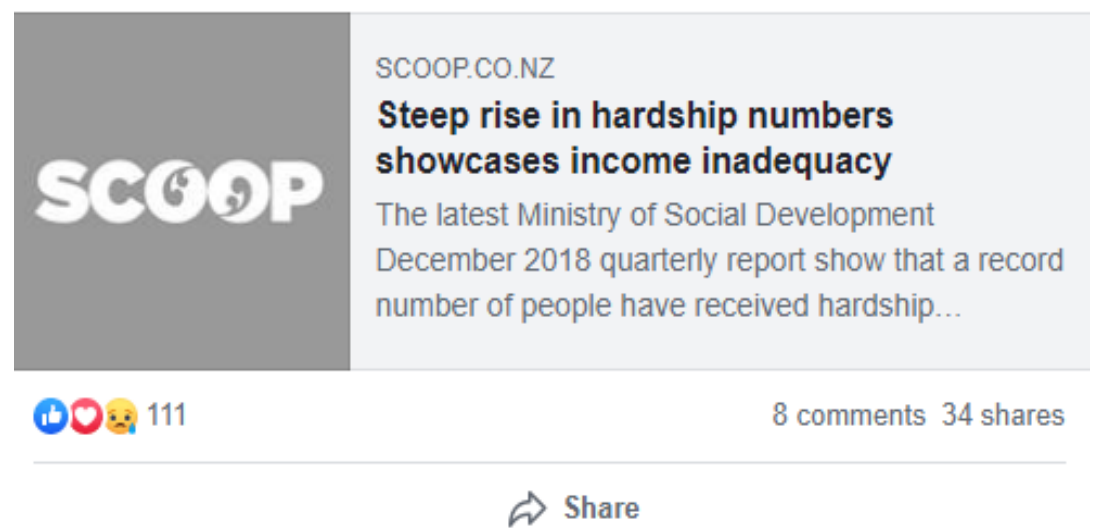

Figure 5: AAAP sharing a Scoop media release through its Facebook page, posted 16 Jan 2019. Image captured 7 Aug 2019.

Like PAPA, AAAP's interviewee also provided a highly conditional appraisal of the affordances of social media technologies, calling them a "one-way megaphone, rather than a way to build relationships". Consequently, AAAP's interviewee emphasised social media much less than traditional media during the interview itself, as they were much more interested in building relationships with individuals in an offline capacity before distributing political messages online. However, AAAP does not neglect social media wholesale; rather, those media play a slightly different role in the organisation's strategy compared to UW's or PAPA's. On the only occasion in which Facebook came up in our conversation, the organisation's interviewee said that:

AAAP interviewee:
The news cycle can often dictate our frequency on social media, but over time we have attempted to use social media tools to explore how our audience is actually active on social media, using Facebook algorithms to maximise the reach when we do decide to post on social media, particularly when they're sort of organic from us rather than reactive to what's happening out there. 
This excerpt demonstrates the organisation's general belief that social media content is dependent on the news cycle, which explains why discussion of its more proactive media work tended more toward the traditional media. The excerpt also demonstrates that like UW, AAAP uses Facebook's Insights feature to gain a better understanding of its audiences' media use. By capitalising on the affordances of this feature, AAAP ensures that when it does invest more resources in social media, it knows how to make itself as visible as possible.

AAAP's interviewee did not explicitly discuss the other social media platforms used by the organisation, such as Twitter. However, my supplementary analysis of AAAP's media use (including social media) shows that the organisation mainly uses Twitter to 'retweet' news stories and supporting commentary, as well as to share links to its media releases. Taken together, these strategies indicate that AAAP is trying to reach its audiences by using social media to supplement its efforts in traditional media - at least when it comes to the specific task of entering welfare discourses and influencing media narratives on the topic.

\section{Affordances: conclusion}

Each participant identified a range of technological and communicative affordances that they actively build strategies around to acquire the attention of and facilitate the political activation of their target audiences. UW and AAAP's interviewees described how their organisations use features on social media to gain better-informed understandings of SMOs' audiences, greater control over content, and clearer pathways to acquiring and retaining those audiences' attention, while PAPA's interviewee described in explicit terms how fundamental Facebook's event pages are to facilitating mobilisation. All three participants built their understanding of social media platforms' algorithms into their media strategies as well, navigating their restrictions on the organisations' ability to communicate with their audiences by either manipulating those algorithms or turning to face-to-face modes of communication that better cultivate capacities and motivations for participation. Additionally, AAAP found that traditional news media offer distinct affordances that 
remain uniquely relevant to social movements, such as enabling access to mainstream news outlets' pre-existing audiences (as opposed to ones SMOs must build themselves through social networking), while PAPA found this affordance to be especially valuable for acquiring the attention of prisoners. Participants collectively identified a range of communicative affordances across their engagements with news media that addressed capacity and motivation for participation in some way, but the technological affordances of the news that they identified tended more toward addressing how social movements navigate the attention economy. Given the complexity inherent to considering all the affordances of the platforms, outlets and means of communication used by the participating organisations, each interview evolved into a discussion of how other factors inform their media and communication strategies.

\section{Conflict}

Donatella della Porta and Mario Diani (2006) establish a framework for what constitutes a social movement which, amongst other criteria, requires involvement in "conflictual relations with clearly identified opponents" (p. 20). Because media have become a significant site for the production and distribution of information (Melucci, 1994, p. 110), so too have they become an increasingly significant site of struggle between SMOs and their opposition. Participants described how their organisations navigate conflict with oppositional actors who seek to either mitigate the impact of SMOs' media presence or eliminate that presence entirely, since such efforts impede organisations' efforts to acquire the attention of their desired audiences. In some cases, however, participants described how they used these conflicts to their advantage as well by highlighting ways of getting involved in their respective movements' struggles. 
Conflict - UW

Because UW is technically a local affiliate council and not itself a union, its interviewee described how the organisation cedes space in news coverage of large-scale industrial disputes to those unions and their workers to speak for themselves. As a result, the organisation does not come into direct confrontation with employers in the media as often. However, it does assume a strategy designed to ensure its constituent unions' confrontations are visibly supported by workers in other sectors and the public more broadly:

UW interviewee: By having something just slightly off to the side [in the news], representing a different sort of thing, we can find people who are teachers, nurses, whatever else to speak in support of public transport workers, for example.

Though it takes place through the same outlets as unions' news coverage, UW's interviewee described how this "off to the side" strategy makes support outside of the industry more visible in situations of conflict. While AAAP is often front and centre in its conflict with MSD and draws support from its base to do so, UW's constituent unions clash with their employers directly instead while UW supports them from "off to the side" by highlighting the perspectives of ordinary people outside those organisations. This strategy to navigating industrial conflict opens up new means of participation in workers' struggles beyond actually working in the affected industry.

In the public transport example mentioned in the above excerpt, a rail union in Te Whanganui-aTara/Wellington went on strike in November 2017, threatening to shut down commuter trains for 24 hours and do so repeatedly until its demands for fairer working conditions were met (“Wellington Trains Grind to Halt", 2017). In the build-up to the day of the strike, UW's interviewee said the organisation generated "thousands" of signatures from public transport users in the region to demonstrate their support for the striking workers, despite the impact of the shutdown on those commuters. When the union called off the second strike day of the month after the employer backed down, national news coverage included a UW Facebook post "off to the side" of the main story's focus on the union and its members' employer, as demonstrated in Figure 6 ("Wellington 
Trains to Run on Friday", 2017). The post included an image of UW members holding large placards on which they had gathered signatures from supportive commuters. UW's interviewee believed that this strategy for navigating conflict through media demonstrates how there is much broader public support for public transport workers outside the sector itself than there is for those workers' employers. Highlighting these placards through the media constitutes an action frame, or the "action-oriented sets of beliefs and meanings that inspire and legitimate activities and campaigns" (Benford \& Snow, 2000, p. 614). This particular action frame demonstrates that there are other means of participating in workers' struggles than working in a unionised industry, once again addressing the capacity prerequisite for activation.

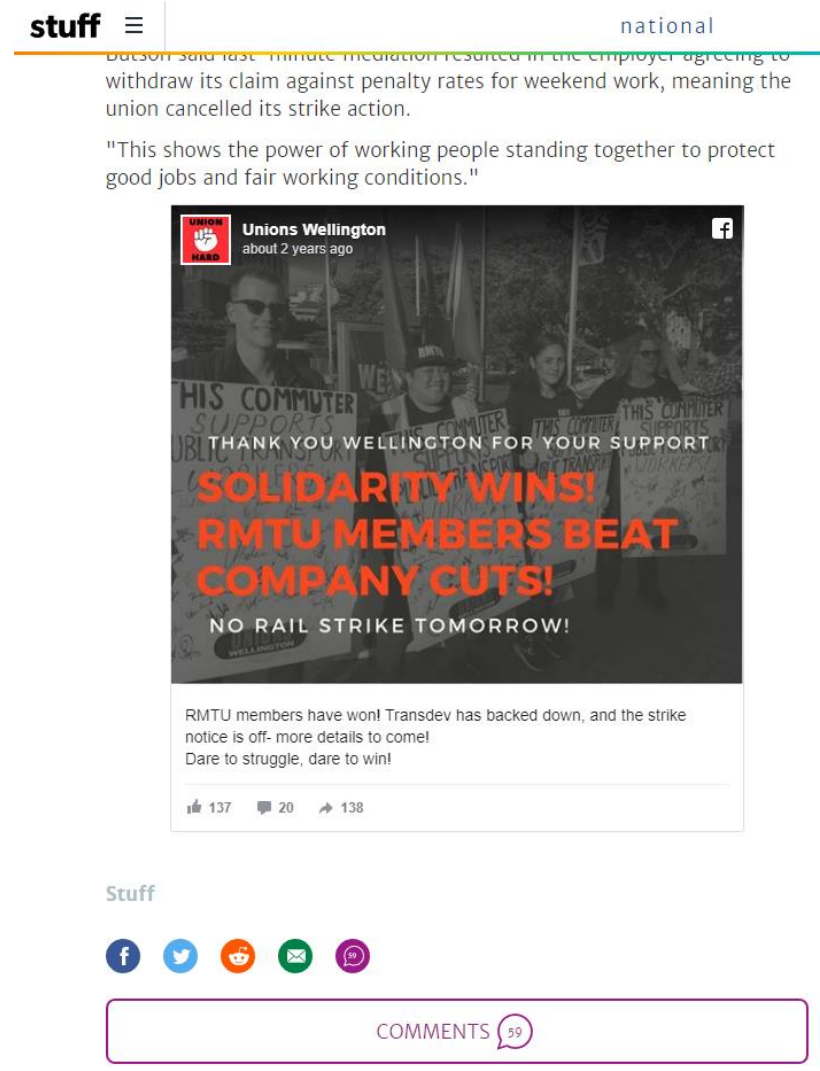

Figure 6: UW's Facebook post is featured in a Stuff article on the same topic. Image captured 23 Sep 2019. 
Conflict-PAPA

As previously discussed, a key component of PAPA's news media strategy is the cultivation of relationships with individual journalists. The organisation's interviewee stressed that investigative journalists in particular are well-accustomed to publishing critical coverage that combines "hard, easily-provable facts and personal stories" to "get the public to care" in ways PAPA sometimes struggles to do. By highlighting the "horrors of imprisonment" in this way, the organisation hopes to justify the necessity of its conflict with its oppositional actors. This strategy hints at attempts to encourage the development in its news audiences of motivations to participate in the prison abolition movement.

Because individual journalists play a pivotal role in PAPA's news media strategy, however, actors opposed to PAPA and the prison abolition movement seek to disrupt those relationships to prevent the organisation and the issues it highlights from receiving coverage. The organisation's interviewee claimed that, despite developing amiable relationships with numerous journalists across the country, those journalists still expect to "get a call" from Corrections, the Police and/or the Ministry of Justice if they publish anything too critical of those institutions. PAPA argues that this dynamic forces New Zealand's press into being the state's mouthpiece, rather than its watchdog:

PAPA Everyday journalists are under so much pressure just to pick up Police press interviewee: $\quad$ releases and republish them, and to pick up official organisations' press releases and just run with them, that when you have something which runs against the mainstream ideology, it's really hard for them to just pick it up. So certainly, the media environment itself is dominated by incredible... pressure from the state itself to publish the state's own press releases, especially from Police and Corrections. And similarly, [journalists] fear repudiation for publishing critical information.

Between the economic pressure journalists are under to minimise their research work, and the political pressure placed on them by state institutions to neglect their watchdog role, PAPA's interviewee sees traditional media as a particularly contentious political arena in which any attention the organisation acquires is hard-won. 
Journalists are not the only people to experience retaliation when a critical story runs, however. PAPA's interviewee described how its attempts to campaign for the wellbeing of individual prisoners through media have occasionally "backfired" despite the organisation's best efforts, rendering those prisoners vulnerable in two instances. In the first instance, PAPA's interviewee described how the organisation tried to help a prisoner it was advocating for speak to a journalist. However, Corrections responded by applying a "very strict reading of [its] regulations", which only allow prisoners to "talk to the specific person you've been approved to talk to on the phone". Because this prisoner was not specifically approved to talk to that journalist, PAPA's interview said that Corrections punished the prisoner with solitary confinement. In the second instance, Corrections responded to PAPA's media work with a prisoner by disclosing the nature of that prisoner's offences to the media. This move undermined PAPA's ability to use the media narrative to connect with its audiences (as well as advocate for this person) by redirecting the narrative's focus from Corrections' alleged human rights violations to the nature of the prisoner's offences.

Taken together, PAPA found that these conflicts significantly restrict its ability to achieve visibility through New Zealand's mainstream news outlets. The organisation's interviewee explained that successfully advocating for individual prisoners through media ultimately requires accounting for PAPA's ability to control the narrative, as well as the possibility of "backlash" against affected prisoners. Aligning with investigative journalists who share a similarly critical eye for institutions like the Department of Corrections highlights one such approach to achieving those conditions, as do the previously discussed means of building offline relationships with non-investigative journalists to encourage their support. Though the examples above suggest that controlling the narrative and preventing backlash can be difficult, the organisation still allocates resources to news media; as previously mentioned, they are among the only media that can reach the attention of the organisation's incarcerated base, for whom information about PAPA's advocacy efforts is especially valuable. 
Conflict - AAAP

Like PAPA, AAAP also expressed concern for a degree of backlash against the members of its base it recruits to speak to the news media. However, we discussed this concern more in terms of how news media treat those people than the Ministry for Social Development, given how much AAAP's media strategy involves its base directly. AAAP's interviewee described how the organisation works to build relationships with beneficiaries such that they trust the organisation "will hold their dignity the best that [it] can while working with media which doesn't always have that in mind." Holding that dignity primarily involves the interview preparation process described previously, but also defending the agency of beneficiaries as a group during media conflicts with the Ministry and other oppositional actors like conservative news outlets.

After Radio New Zealand's July 2019 Checkpoint programme featuring AAAP and a weekly Work and Income queue, the Ministry for Social Development accused AAAP of "refusing" to work with it on shrinking those queues (Blake-Persen, 2019). The Minister herself, Carmel Sepuloni, later accused AAAP of being responsible for the queues to begin with, since they occurred on the same days that AAAP advertised doing its free advocacy services (Daley \& MacManus, 2019). This exchange reflects Koopmans' (2004) notion of 'resonance', which involves “provoking reactions from other actors in the public sphere" (p. 374). Because AAAP's primary opposition actors acknowledged the organisation, it was able to leverage mainstream journalism's values regarding objectivity to exercise a right of reply. The next day's coverage on Stuff (a New Zealand national news outlet) consequently put AAAP in the headline, framing the article as the SMO's response to the Minister's accusations (Daley, 2019). Sepuloni later retracted her accusation on the Māori Television programme Marae (2019), which AAAP's interviewee stressed included a statement that "AAAP does good work". Together, these developments in response to the original Checkpoint story afforded the organisation a level of Koopmans' notion of 'legitimacy' as well, since they signify a "degree to which actors in the public sphere support or reject an actor or her claims" (2004, p. 375). 
However, this narrative did not simply feature a faceoff between AAAP and the Ministry. Though Stuff's online news articles on the story only include statements and social media content from each party's spokespeople, the articles also feature Checkpoint's original video story, which included interviews with numerous beneficiaries in the queue sharing their own stories and predicaments that have driven them to queue up so early in the morning. The narrative constructed through these interviews culminated with an interview with AAAP's official spokesperson, Kathleen Paraha, who argued that many of those people would not receive their entitled benefits without an advocate present-hence the Thursday queues (Blake-Persen, 2019). "Suturing" (Funke et al., 2012) together the organisation's political stance and its base's authentic experiences therefore also helped the organisation redirect scrutiny back toward the Ministry, while simultaneously building the capacity of the spokespeople in the queues to more fully participate in the anti-poverty movement.

AAAP is also not averse to initiating conflict itself. We discussed its openness to appearances on more conservative outlets such as talk radio station Newstalk ZB (see Burrow, 2015; Newstalk ZB staff, 2019), which is generally more oppositional to organisations like AAAP in its welfare narratives:

AAAP interviewee: I think a lot of our audiences to be honest are more Green Party and more to the left, more sort of... progressive Labour voters, potentially? We know that the Mike Hoskings of the world are not our audience necessarily, but it's still useful to insert ourselves into those conversations because it's ultimately about not making the narrative worse than it already is in the public.

Though AAAP's interviewee still considered visibility to be a goal in these more contentious spaces, they argued that such spaces nevertheless afforded additional opportunities to respond to and mitigate damaging narratives. This example further demonstrates how the organisation consciously takes advantage of conflict to gain the attention of viewers who might be less exposed to leftleaning ideas. 
Conflict: conclusion

The conflicts addressed by the three participants reflect not just some of the ways these SMOs' oppositional actors suppress the growth of the participants' movements, but how the participants use these conflicts to their advantage as well. Each participant uses conflict to draw attention to their respective movements, as well as using conflicts as opportunities to showcase action frames for participation in those movements that can address their audiences' capacities and/or motivations for participation. These strategies depend on some degree of existing popular support, however; PAPA's conflicts with Corrections, Police and the Ministry of Justice are primarily over the very visibility of prison abolitionist ideas in public discourse, let alone using that visibility to facilitate activation. Comparatively, UW and AAAP demonstrate the ability to showcase means of participation through their conflict-driven media in addition to generating attention, which suggests that attention is itself required to address the other prerequisites of political activation in a social movement.

\section{Movement overlaps}

Participants communicated action frames (Berenson \& Shaw, 2004) through their media activities that spoke to values and goals which overlapped with other organisations and movements. These action frames appeal to the participants' movements and others simultaneously by identifying and cultivating motivations for cross-movement participation. In doing so, participants hoped to mobilise people who were more inclined toward participation in other movements by appealing to their reasons for participating those movements. Importantly, those movements did not necessarily have to be engaged in class politics; participants frequently worked with New Social Movements to increase their collective mobilising capabilities rather than compete with each other in the attention economy. 
UW's strategy for capitalising on the opportunities presented by movement overlaps closely resembles "social movement unionism", a strategy in which unionists incorporate new constituencies into the union movement "through alliance-building with civil groups and other social movements [beyond] the workplace" (Parker, 2011, as cited in Newman \& Jess, 2014, p. 3). Accordingly, UW's interviewee was the most explicit of the three research participants regarding overlaps between their own movement and NSMs. Their broad definition of 'working class issues' opens the organisation up to an approach which closely resembles social movement unionism:

Interviewer: $\quad$ How would you define 'working-class issues'?

UW interviewee: Working people's issues are just those which affect working people's lives, which is pretty much everything. I think climate change is the best example; you can't have good terms and conditions in your workplace if climate change is going to make food harder to get in the future.

Though the organisation's interviewee did not name social movement unionism directly, they did cite the "experimentation" with movement overlaps done by one of its constituent unions which previously campaigned for human rights related to migrants. Using this example as precedent, UW's interviewee then evoked environmental issues, the "peace movement" and "social justice issues" throughout our interview as concerns which did not directly relate to working-class politics but were nonetheless relevant to the "working people" comprising UW's base.

UW's interviewee described instances in which its objectives and those of NSMs have aligned as "natural links" that incentivise cooperation. They first used the term while describing the period during which UW began organising on behalf of striking bus drivers in Te Whanganui-aTara/Wellington in October 2018. After establishing a strike fund on behalf of the drivers, the organisation received a donation from the environmental SMO Oil Free Wellington (OFW). In addition to donating to the strike fund, OFW also made a public statement articulating why workers' rights mattered to its own struggles for a "just transition" to a more sustainable transport industry (Oil Free Wellington, 2018a). This statement took the form of a press release distributed via 
"community news outlet" Scoop, which was also then circulated on Facebook by OFW and UW, and on Twitter by OFW (Oil Free Wellington, 2018b; Unions Wellington, 2018). The link demonstrated by this solidarity action showcased an action frame for contributing to the union movement that would appeal to people who are already invested in environmental politics, but who may not already have what UW's interviewee described as an "impulse towards" union politics.

Identifying the points of overlap between the union movement and NSMs occasionally proves challenging for UW, however. Despite some vague mutual resonance with a broadly-defined political left, UW's interviewee believed that the goals of class movements and ostensibly leftaligned NSMs only "very occasionally" relate to each other:

UW interviewee: We want the union movement and workers' rights and inequality to be overlapping with more social justice sort of politics I guess, and oftentimes those two things are quite divergent. In a union world, in a socialist world [we] sort of think of things in quite distinct ways, and organise in quite distinct ways, and very occasionally bump into [NSMs] or relate [to them]. I think those two things should be infused, and I think there's a useful crosspollination; there's social justice challenging things and pushing things through and being very enthusiastic, which would be helpful in the union movement, but a seriousness of organising and resourcing would be very helpful in that sort of social justice thing.

Here, they delineate between "socialist" and "social justice" movements as distinct struggles that should ideally be intertwined. This recognition of differences between the union movement and "social justice" movements suggests an understanding of their differing structures and the action frames which might be required to appeal to each, but not necessarily how to "infuse" those structures or goals on a sustained basis. UW sees such infusion as ideal, however, because it streamlines the process of activating people into working class politics via NSMs.

Movement overlaps - PAPA

Instead of emerging from a traditional class movement and incorporating NSM elements where possible to broaden its scope, PAPA's original incarnation No Pride in Prisons (NPIP) displayed 
more NSM qualities from the outset. PAPA always saw this queer and trans focus as part of a larger movement:

PAPA We started as a protest against Police and Corrections involvement in the interviewee: $\quad$ LGBT Pride parade in Auckland in 2015. We kind of spontaneously formed in reaction to that under a different name, No Pride in Prisons. Then subsequently we switched tack and became concerned with broader issues of criminal justice than just issues relating to queer and transgender people.

The organisation described how its founders had originally connected through a reading group focused on queer and trans politics, which "laid the groundwork for [their] thinking around a queer politics of prison abolition" (Lamusse, 2018, pp. 122-123). This sentiment provided the initial action frame for the Pride parade protest described above by appealing to overlaps between class and queer/trans concerns regarding prisons. PAPA has since framed this overlap as "a political space where our mutual relation to domination gives us the opportunity to fight together", referring to the queer, feminist, decolonial and anti-capitalist politics that the organisation found to be suppressed by New Zealand prisons ("No Pride in Prisons on Abolitionist Politics", 2017, pp. 131-132). From the start, then, the organisation theorised that the prison abolition movement itself presents a significant site of overlap between the objectives of class movements and NSMs.

One of these sites of overlap takes place between the prison abolition movement and indigenous sovereignty movements. As mentioned previously, the organisation has prioritised having a Māori spokesperson represent it in traditional media. This enables the organisation to showcase action frames which speak specifically to Māori, from a Māori standpoint. An example of this can be seen in a media release published by the organisation announcing and explaining its name change from 'No Pride in Prisons' to 'People Against Prisons Aotearoa'. In this release, the organisation's press spokesperson is quoted as saying "People Against Prisons Aotearoa, or PAPA, is a reminder that Papatūānuku underlies the struggle for mana motuhake $\mathrm{e}^{27}$ and the nationwide liberation of Māori in Aotearoa" (No Pride in Prisons, 2017). In te ao Māori, Papatūānuku is the Earth

\footnotetext{
${ }^{27}$ Māori self-determination.
} 
mother who "gives birth to all things" (Charles Royal, n.d.). PAPA includes her in this statement (and in the organisation's acronymised name) as a way of linking her to the organisation's kaupapa, a discursive choice specifically intended to resonate with Māori audiences. This statement therefore argues that participation in movements for Māori self-determination naturally overlaps with the prison abolition movement.

PAPA has also identified movement overlaps with local SMOs aligned with the global peace movement, which seeks the end of wars and violence (Locke, 1992). In a press release announcing that the organisation would be joining Peace Action Wellington (PAW), Peace Action Hamilton (PAH), Auckland Peace Action (APA), and Peace Action Manawatū (PAM) in their blockade of a "weapons expo" hosted by the New Zealand Defence Industry Association (NZDIA), PAPA identified private prison company Serco as one of the attendees alongside international weapons manufacturers (People Against Prisons Aotearoa, 2018). The organisation used this information to connect prison abolition with the peace movement by identifying the NZDIA Forum as a site which united their oppositional actors, and therefore their movements.

Given PAPA's belief in the unpopularity of prison abolition politics, as described previously, identifying these movement overlaps helps to build much-needed support for the organisation's mobilising capability. PAPA has constructed action frames that provide motivations for being opposed to the prison system through support of queer politics, indigenous self-determination, and peace movements, let alone fitting prison abolition into anti-capitalism more generally. As a result, the organisation is able to generate goodwill for its politics which its interviewee argued is only more easily attainable through intentional, face-to-face conversations.

Movement overlaps - AAAP

AAAP's interviewee did not discuss movement overlaps as explicitly as UW and PAPA. However, they did identify some of AAAP's organising strategies which were specifically oriented around the racialised and/or gendered needs articulated by its base (at least inasmuch as they 
related to poverty), as well as one campaign which explicitly drew on wider organisational coalitions (if not other movements necessarily) in order to achieve its objectives. Together, these approaches produced action frames which appealed not only to a larger working class, but to the social identities within that class that are more often the focus of NSMs.

Consciousness of these social identities and the specificities of their experiences are evident in AAAP's publications. Its core demands document, AAAP SAYS STOP THE WAR ON THE POOR (\#NOTENOUGHLEFT), highlights the impact of New Zealand's welfare system on a diverse range of people from its base by deploying the personal narratives of people from Māori, Pasifika, Pākehā, Iranian, and gender diverse backgrounds. The following example comes from a supporter of AAAP's second demand, to "redefine relationships based on whānau, not finance":

Māori understandings of whānau are not understood by Work \& Income. This includes Unsupported Child Benefit payment paid to those who whāngai ${ }^{28}$ children. AAAP had a case where a woman was not paid for looking after her grandchildren for 10 years. She was recently back-paid $\$ 166,000$. Further to this, Work \& Income only consider the family unit to be immediate family meaning they resist supporting people going to tangi ${ }^{29}$ for extended whānau members. 'They say he tangata, he tangata, he $\operatorname{tangata}^{30}$ on the walls of Work \& Income but they don't value our whakaaro ${ }^{31}$. What we value as success is linked to whānau, to looking after the next generation.' - Māori/Samoan Sole parent, 1 child (Auckland Action Against Poverty, 2017, p. 8)

Narratives like this one not only establish that the demands themselves have cross-cultural relevance but showcase action frames that can "organize [those] experiences" in a way that can "guide action" (Benford \& Snow, 2000, p. 614). In this case, AAAP is attempting to "guide" the state

\footnotetext{
${ }^{28}$ Foster, adopt.

${ }^{29}$ Funeral.

${ }^{30}$ Of the people, for the people, by the people.

31 Thoughts, perspectives opinions.
} 
toward answering the \#NOTENOUGHLEFT demands. The organisation's interviewee described how structuring the organisation's action frames in this way means that "political messages are coming from the people who are actually having those lived experiences". Such a strategy becomes even more targeted when those messages are filtered through the representation of beneficiary struggles specific to the diverse backgrounds represented in the document. The \#NOTENOUGHLEFT demands do not specifically refer to or hail any of the indigenous, antiracist, queer or disability-related movements that might be relevant to people from these backgrounds. However, the document does organise those experiences into action frames for becoming involved in a more class-oriented beneficiary activism, articulating potential motivations for participation in the anti-poverty movement through identity-based lenses as much as a class one.

AAAP's interviewee identified a slightly greater degree of movement overlap through its individual campaigns. The key example we discussed was the organisation's campaign to end the state's imposition of benefit sanctions on sole parents:

AAAP With our campaign to end benefit sanctions on sole parents, I think that was interviewee: a really successful one in terms of building broad support, particularly from groups that may not necessarily be people on the benefit specifically... We launched a campaign in 2016, and we got a variety of groups that perhaps already had access to a lot of those more liberal audiences, and that kind of helped make our issue more palatable I guess to an audience which would perhaps normally see us as quite radical.

Part of what made the campaign more "palatable" was how this "variety of groups" rearticulated the issue through action frames targeting people situated outside of beneficiary politics. We discussed how this policy "affect[ed] mothers primarily" and had direct ties to impoverishment, which made the campaign an ideal point of intersection for class and feminist politics in particular. We did not discuss, however, whether this campaign utilised any overlapping interests with feminist SMOs; the action frame for this overlap effectively argues that poverty disproportionately affects single mothers, further restricting the agency of those women through simultaneous class and gender-based oppression. 
Other groups involved in the campaign tended to engage with part of AAAP's understanding of the issue, but not all of it. Though we did not discuss feminism itself during our interview, the groups with "more liberal audiences" AAAP's interviewee described above expressed some feminist sentiments in their own media appearances. For example, then-Green Party co-leader Metiria Turei criticised the sanctions as "misogynistic" based on her own experiences of being on the benefit, emphasising the gendered aspects of the issue through their financial impact on families (as cited in Harris, 2017, para. 12-14). Other organisations utilised class more in their action framing, but did so in terms that would better resonate with their "more liberal audiences". The charity Child Poverty Action Group (CPAG) acknowledged some of the gendered components of the sanction, citing the mother receiving the sanction rather than the father as evidence that the policy is heavily flawed, but emphasised the material impact on children most of all (2017). Both of these examples featured action frames oriented around "families" or "children" to appeal to liberal audiences where AAAP's more "radical" framing around the issue of poverty more broadly did not.

Because AAAP was able to appeal to people across liberal New Zealand and the Parliamentary left through campaign support by these charities and parties, it was able to engender a degree of cross-class motivation to act on behalf of single parents - if not the wider issue of benefit sanctions itself. Three months after our interview, the Coalition Government led by the Labour Party announced that, among other "sweeping" welfare reforms, it would be ending the sanction on sole parents (Flahive, 2019). ${ }^{32}$ Of these reforms, however, ending the sanction on sole parents was the only one that explicitly met any of AAAP's demands (Auckland Action Against Poverty, 2019b). The other demands lacked not only the same duration and scale of campaigning, but also the same number of possible action frames from which to generate the kind of crossorganisational (if not cross-movement) support that brought the issues with sole parent sanctions to

\footnotetext{
${ }^{32}$ The organisation's interviewee claimed that Sepuloni acknowledged AAAP's work on the issue in her announcement of the reforms at a public meeting in West Auckland, similar to how she retracted her accusations that AAAP was responsible for the early morning queues at the Manurewa Work and Income office.
} 
mainstream attention. This juxtaposition suggests that a diversity of action frames, whether motivated by feminist politics or a stance against "child poverty", was an essential component of AAAP's campaign strategy.

Movement overlaps: conclusion

Uniting all three participants in their bids to capitalise on movement overlaps was how either they or their allies in other movements and/or organisations used media releases to articulate the action frames enabled by those overlaps (Auckland Action Against Poverty, 2019b; "Harsh Punishments for Sole Parents", 2017; No Pride in Prisons, 2017; Oil Free Wellington, 2018a; People Against Prisons Aotearoa, 2018). By showcasing motivations for participation beyond those usually expressed by participants of a given movement, organisers for those movements were able to extend audiences' existing attention to additional political arenas. Participants were consequently not only inclined to invest in the politics of other movements in order to identify and develop further connections, but also to find ways to build coalitions with SMOs in those movements on a more sustained basis.

\section{Conclusion}

Each of these themes represents a theoretical object that informs the strategies SMOs use to build their movements by navigating the attention economy to politically activate their audiences. Participants identified how specific social media platforms, news outlets and other means/modes of communication helped them determine what their movements can do to navigate the attention economy and build up the capacity, motivation, and mobilising abilities of their audiences. Each participant interpreted these affordances differently, however, based on differences in their movements' specific sociopolitical contexts. Similarly, participants found that depending on their context, the conflicts they engaged in through their movements foreclosed some opportunities to 
acquire the attention of potential movement participants and/or opened up other opportunities for generating the capacity and motivation for participation. Finally, participants considered how they incorporated movement overlaps into their strategies in order to generate a wider range of motivations for participation that could encompass other organisations and movements. They achieved this through developing a repertoire of action frames that extend well beyond the traditional reasons for participating in class movements into those more commonly expressed through NSMs. The next chapter considers in further detail what these findings contribute to existing research on the attention economy, political activation and social movements. 


\section{Discussion}

The previous chapter established three key themes that spoke to the theoretical objects participants build their strategies around for facilitating the political activation of their organisations' audiences. In Bode and Becker's (2018) model, political activating people into fully participating in political affairs requires potential participants to meet three conditions: they must have the capacity or the knowledge and skills necessary to participate, the motivation to participate and a political activity to mobilise around/participate in (p. 1574-1575). However, this model does not account for how this research's findings also speak in myriad ways to the attention economy, in which information is in plentiful supply and human attention is scarce.

Reflecting on how the themes generated by this analysis influence the development of social movements, the issue of affordances addresses participants' understandings of how various media technologies and means/modes of communication enable and constrain what those participants can do to acquire the attention of and mobilise their target audiences. To a lesser extent, the affordances theme also reflects how media can address the capacity for political participation, while the non-mediated communicative tools at SMOs' disposal better afford the cultivation of motivation for participation as well. The conflict theme, meanwhile, establishes how participants not only navigate the barriers to visibility (and therefore attention) posed by their oppositional actors, but also how they use those conflicts to their advantage by modelling through them what participation in their social movements looks like. This kind of strategy helps build the capacity for participation by providing an opportunity to distribute the knowledge (and to some extent, skills) necessary for participation, as mentioned above. Finally, the movement overlaps theme considers how participants built strategies for cultivating a wider range of motivations for participation by identifying points of common interest between organisations and movements. These strategies demonstrate the potential for pooling together the wider activation efforts of movements' networks. 
While each of these themes are generalised to some extent between participants in the sample, those participants' interpretations of the themes varied significantly based on their specific sociopolitical contexts. Therefore, this chapter addresses the value of the findings of my thematic analysis on two fronts. Firstly, the findings present a techno-social challenge to the democratic thesis, or the idea that technology will "save democracy by bringing it to the people" (Dean, 2009: p. 36). Because participants have access to similar technologies but develop very different media and communication strategies around them, I argue that those technologies are not actually equal in what they afford to each group due to the capitalistic qualities of the attention economy that they enable. This analysis therefore demonstrates that even though information and communication technologies are more accessible than ever, the very accessibility of these technologies end up constraining SMOs' efforts to participate in public discourse as much as they enable those efforts. Secondly, affordances, conflicts and movement overlaps speak to how the political activation of social movements operates in the attention economy. While the themes describe how participants developed diverse, context-informed strategies for building their movements, what unites those strategies is how they contribute to the growth of their own movements and larger networks of movements by acquiring attention, building capacities, establishing motivations and providing opportunities to mobilise. The themes therefore build on Bode and Becker's (2018) political activation model by repurposing its emphasis on civic participation for use in a social movement context.

\section{Affordances}

Understanding how (and when) social movements incorporate ICTs into strategies for politically activating new participants requires grappling with how the attention economy informs the ways individuals, institutions and movements communicate. The affordances theme demonstrates how participants do so by orienting their entire media and communications strategies 
around what they perceive being able and unable to achieve with each of the tools at their disposal. However, the differences between participants' descriptions of their strategies varied based on what they were trying to achieve politically, suggesting that the affordances of ICTs are not as equally accessible as the democratic thesis purports.

To start, participants identified how specific social media features afford deeper understandings of their [networked] audiences and those audiences' media use; the redistribution of already-made content to those audiences; the frequent and/or consistent distribution of content to those audiences more generally; and the mediated mobilisation (Lievrouw, 2011) of those audiences. Participants universally described using these affordances to overcome what they saw as the constraints on their ability to reach audiences through social media, particularly as those constraints manifested through perceptions of the platforms' content filtering algorithms. Between UW's "fluff" and "serious" content plan for "feeding" the algorithm, PAPA's insistence on regular content and AAAP's use of algorithms to time the delivery of their own content, participants' strategies focused to some extent on acquiring attention. However, they more strongly describe strategies through which attention can be retained long enough to facilitate the mobilisation of the organisations' audiences, which at least in part involves using Facebook's event page feature. Such goals indicate that the participating SMOs value the attention their social media strategies generate and retain because those strategies enable the ability to connect audiences to opportunities for participation.

However, where the participating organisations' strategies vary is in what they emphasised most, which varied based on their sociopolitical contexts. UW's interviewee assumed existing support for working class politics; accordingly, the organisation sees social media as a tool less for expanding on those politics but on building the capacity to mobilise by using its Facebook content to showcase what participation in the union movement looks like. In comparison, PAPA's social media content focused far more on articulating the organisation's politics, since organisation's interviewee 
assumed there was not only a lack of existing awareness, but outright hostility to prison abolitionism as a result of that lack of awareness. AAAP, meanwhile, de-emphasised the value of social media in generating attention, capacity or mobilisation because many of its opportunities to address those prerequisites are folded into its strategies involving news media and face-to-face interactions. The differences between how each organisation uses social media highlight how the affordances of ICTs are constrained by sociopolitical context; depending on how well-established an organisation's politics are in the public sphere, that organisation can devote less effort to drawing attention to the issues it is organising around and more toward building its audience's capacity to mobilise around those issues.

Participants found that the affordances of traditional news media, meanwhile, more universally oriented around acquiring attention. Participants believed that news media uniquely enable access to mass audiences, whose attention can then be directed to anything the organisations thinks is strategically pertinent. However, how participants described acquiring the attention of these audiences and what they directed that attention to within their movements once again varied significantly based on their sociopolitical contexts. In UW's case, instead of representing unionised workers directly through news narratives focused on them, as its constituent unions do, the organisation seeks to "enlarge political participation" (Melucci, 1980, p. 204) in the union movement more broadly by either focusing on the "off to the side" perspectives in those narratives or by focusing on issues facing workers who are not themselves unionised. PAPA's interviewee, meanwhile, emphasised that whatever attention the organisation acquires must in some way extend to its incarcerated audience; as a prisons-oriented SMO, PAPA is more concerned about this audience than the other participants in the sample. Finally, AAAP's interviewee drew more attention than the others to its efforts to approach and engage with conservative news outlets as much as any other in order to "mitigate" those outlets' more damaging welfare narratives. Thus, similar to social media, there is a correlation between social movements' specific sociopolitical contexts and how those movements' organisers interpret the affordances of news media. 
These correlations suggest a degree of inequality in how SMOs access the public sphere. Koopmans' (2004) selection mechanisms for that sphere help to explain how this inequality manifests. These mechanisms - which can afford "visibility", "resonance" and "legitimacy" to movements and their activities- help SMOs acquire the attention of mass audiences through mass media (p. 375). However, because those mechanisms operate within an attention economy, they confront SMOs with a paradox. Without the selection mechanisms offered by institutionalised news media or the content personalisation algorithms offered by social media platforms, audiences experience "sensory and information overload" (Dean, 2016a, p. 64), causing SMOs' messages to get lost in the mass circulation of content. With those selection mechanisms, however, SMOs require great amounts of attention to do anything related to political activation with their news media visibility beyond attracting more attention. While news media can potentially afford "resonance" and "legitimacy" in addition to visibility to a mass audience, as AAAP's news narrative regarding the Manurewa Work and Income office queues demonstrates, such instances are "the rare exception" (Koopmans, 2004, p. 371); usually, these selection mechanisms function more as filters for the attention economy that gatekeep the attention of mass audiences. Despite claims by proponents of the democratic thesis that the internet (and thus social media) will open up access to those masses, by those masses, participants' descriptions of their media strategies uniformly demonstrated an understanding that news media continue to be a quintessential tool for acquiring attention, while also finding that social media are better suited to retaining that attention. Indeed, AAAP's interviewee observed that their organisation's social media content is almost entirely "dependent on the news cycle". Though today's news values may be informed by how much social media traffic a story can generate (Harcup \& O'Neill, 2017), the democratisation of news predicted by the democratic thesis has still not come to pass; "the main role performed by the bulk of the online audience seems to be and disseminating news on social media platforms" (pp. 1474-1475). In other words, SMOs remain constrained in their ability to acquire attention by news media's selection mechanisms. 
Participants also described ways of reaching their movements' desired audiences that did not involve navigating the various attention filters used by social and traditional news media at all. These were unmediated, face-to-face interactions which afforded participants the ability to have more empathic, nuanced dialogues with their audiences through which they could develop more personal relationships. ${ }^{33}$ This kind of outreach obviously operates on a much smaller, one-on-one scale compared to media technologies, but its significance to the affordance theme echoes McAlevey's (2018) appraisal of such strategies as an essential component of organising for the union movement (pp. xvii, 12).

Once again, the strategic purpose for each participant's use of face-to-face interactions varied based on their political contexts. UW's interviewee described how the organisation sends delegates to meet with workers in their workplaces in person when it can, a process which it uses to help build the union movement's presence in its primary site of struggle (the workplace). The interviewee also described how these interactions involved networking via Facebook, so those people can maintain a connection to UW through exposure to its social media. Meanwhile, PAPA's interviewee emphasised the importance of speaking to journalists face-to-face for building relationships with them. These relationships ensure that the organisation is more likely to earn news coverage that can, among other purposes, reach its incarcerated audience. Finally, AAAP's interviewee repeatedly evoked how the organisation works extensively with its constituents in person on the streets where they queued outside various Work and Income offices in Tāmaki Makaurau/Auckland. While this work typically involves advocating on behalf of beneficiaries to their case workers, it also involves recruiting and training them to speak to journalists, as described previously. What stands out about these examples, however is that none of them are wholly disconnected from media; rather, the mediated communications are closely imbricated with their face-to-face interactions. Participants generally believed that interacting with people through media

\footnotetext{
${ }^{33}$ AAAP's interviewee used the Māori term "whakawhanaungatanga" to describe the process of establishing relationships in the context of offline meetings.
} 
after communicating face-to-face is more convincing, and can therefore increase the likelihood that those people eventually feel sufficient motivation to contribute to participants' movements in some way. These affordances therefore begin to address one of the political activation prerequisites that participants' understandings of the affordances of media technologies did not encompass as thoroughly. Such strategies demonstrate that while many of the communicative tasks necessary for growing social movements can now be achieved through ICTs, they cannot entirely supplant the value of human presence.

Mapping out the affordances of ICTs and other tools at organisers' disposal enables them to identify which of those technologies best generates the attention of their audiences in order to cultivate those audiences' capacity and motivation for mobilisation. This process demonstrates the theme's utility in applying a political activation model to social movements. However, the affordances theme also highlights how unequal the playing field is for social movements due to the nature of their politics and how they relate to the public sphere. The conflict theme highlights the inequality of the attention economy in greater detail.

\section{Conflict}

How participants determined the affordances of the ICTs and other tools available to them was also informed by the conflicts they engaged in with their oppositional actors. This process involved using one of the most defining characteristics of social movements - "conflictual relations with clearly identified opponents" (della Porta \& Diani, 2006, p. 20) - to address political activation prerequisites by drawing attention to the injustices wrought by their oppositional actors. In some cases, doing so involved highlighting means of participating in the movements against those actors; in others, it involved articulating possible motivational frames for participating. Many conflict situations did not play out as smoothly for participants, however, especially in PAPA's case wherein its interviewee explained how the organisation fought to simply be visible in the media while its 
opponents dedicated resources to preventing even that. Without enough visibility to acquire and retain attention, conflict's ability to facilitate opportunities for meeting the prerequisites for political activation is constrained by its own double-edged nature, reinforcing the dependence of political activation in social movements on attention.

The differences between these conflicts strongly suggest an unequal footing between movements and their oppositional actors that can be better understood in terms of the attention economy. If attention is itself a currency, as Davenport and Beck (2001) contend, then some actors will acquire more attention than others, and as Dean (2014) argues, the very structure of the attention economy is "characterized by competition, division and inequality" of such resources (p. 8). The conflict theme builds on Dean's argument by demonstrating how these qualities of the attention economy manifest in the conflicts contemporary social movements engage in. The state institutions and corporate entities comprising the participating organisations' oppositional actors have the resources to better compete in the attention economy than the SMOs in the research sample, whose memberships and audiences are considerably smaller in comparison. ${ }^{34}$ PAPA even claimed that its oppositional actors in the state engage in anticompetitive tactics like intimidating journalists into not running critical stories, indicating some degree of control over news media platforms themselves. These conditions within the attention economy mirror the material and institutional inequalities between the participating SMOs and institutions they oppose, demonstrating that rather than enabling participation in democratic processes, the attention economy represents an extension of the logics of capitalist accumulation in another, nonmaterial market.

The conflict theme in particular therefore answers Hetland and Goodwin's (2013) call to reinsert an analysis of class and capitalism into social movement studies by demonstrating how

\footnotetext{
${ }^{34}$ Though UW's constituent unions operate on a much larger scale than UW itself, the organisation's interviewee stressed that they are less interested in media campaigning than in the more "immediate" tasks of negotiating collective agreements and representing its members, as described previously.
} 
capitalism influences the attention economy and therefore the media practices of social movements. Hetland and Goodwin argue that the LGBT movement's inception depended on capitalism's expansion of wage labour in the post-industrial era, which enabled people to live in "communities based on sexualities and lifestyles" instead of in reproductive households (p. 93). The conflict theme applies this logic in a different setting by demonstrating that conflict through media is itself dependent on the expansion of capitalist production into nonmaterial realms like information, as participants produced "symbolic representations, frames, and discourse" that they could use to "compete" with their oppositional actors (Lievrouw, 2011, p. 153). The influence of capitalism on these conflicts therefore extends to the affordances of the tools SMOs' use as well, since organisations largely use those tools for meaning-making and agenda-setting. Even for NSMs, who engage in similar conflicts through media, an analysis of capitalism's influence on the attention economy through the conflicts waged over its resources is therefore useful. The similarities between the conflicts waged by class-based movements and NSMs - and how those similarities enable their "infusion", in the terms of UW's interviewee - are explored further through the movement overlaps theme.

\section{Movement overlaps}

Between the repercussions of conflict and limitations to the affordances of ICTs and other communicative means, myriad factors foreclosed the possibilities for participants to acquire the attention of their target audiences through media. However, participants found other strategies for facilitating political activation and growing their movements. The most significant of these strategies involved focusing on audiences whose attention would be easier to acquire since they had already met other prerequisites for activation through involvement in other movements. The research participants described a strategy in which their organisations articulate movement overlaps through action frames (Benford \& Snow, 2000). These frames are then distributed through connective action 
(Bennett \& Segerberg, 2012b), using digital media to distribute them to those organisations' wider networks in order to acquire the attention of people in other movements, including NSMs, whose values and goals are encompassed by those overlaps. Once their attention is acquired, it is easier to mobilise people who are active in other movements because their capacity and attention prerequisites are already met; the only prerequisite missing, and the one action frames articulating movement overlaps address, is the motivation for cross-movement participation.

This strategy demonstrates how contemporary class movements rely to some extent on what Lievrouw (2011) calls the "mutability" of their action framing, which involves using "digital media technologies to create, sustain and reorganize network ties among loosely affiliated alliances of movement participants" (p. 153). Lievrouw theorises that mutability demonstrates how contemporary social movements mirror the "open-source and peer-to-peer architectures" of the networked technologies that they use, resulting in entire movements structured around horizontal networks. Castells (2012), on whose work Lievrouw draws to make her own claim (2011, p. 149), goes so far as to say that these "networks of networks... can afford not to have an identifiable centre" (p. 221). This research builds on both scholars' claims, however, by focusing on contemporary class movements, which simultaneously exhibit some degree of centralisation ${ }^{35}$ and mutable networked activity. Movement overlaps in this case do not demonstrate loose ties among individual movement participants so much as ties between organisational nodes from different movements with loosely overlapping goals. Strategies involving action frames that articulate those overlaps therefore require some degree of structure (provided by SMOs) to link network nodes across movements as much as within them.

In terms of political activation, SMO strategies involving movement overlaps specifically articulate motivations for mobilisation that appeal to participants of different movements. However,

\footnotetext{
${ }^{35}$ Each SMO in the research sample has at the very least an authoritative body from which I procured additional consent signatures to conduct this research.
} 
such strategies contradict McAlevey's assertion that organising a successful social movement has to involve people who "don't consider themselves activists at all" (p. 10). Using movement overlaps to better coordinate networks of existing activists more closely resembles an "option for change" that she calls "mobilizing". In McAlevey's terms, mobilising for change relies on the same activists who "show up over and over" to political actions, rather than on building a mass base of ordinary people (p. 12). The approach is more concerned with existing activists who are already capacitated and motivated to participate in their own movements - they only require motivation to mobilise for movements adjacent to their own. McAlevey juxtaposes mobilisation with an "organizing" model that "places the agency for success with a continually expanding base of ordinary people, a mass of people never previously involved" (p. 10). Interpreting McAlevey's mobilising concept in political activation terms, mobilisation is only one of the prerequisites of Bode and Becker's model (2018, p. 1575), while organising for change fundamentally requires the achievement of political activation on a mass scale.

This interpretation might suggest that strategies involving the articulation of overlapping action frames are limited in their scope. However, what it demonstrates is that participants' other strategies discussed up until this point are designed for the construction of movement bases that can be collated for larger mobilisations through their networks. Their movements are so diverse and their strategies equally so to appeal to the wide range of more "personalised action frames" that Bennett and Segerberg (2012) argue motivate political participation today. The movement overlaps described by my participants therefore enable their organisations to pool together the activation efforts of a diverse range of movements in a way that reflects the networked qualities associated more strongly with NSMs as opposed to traditional class-oriented movements. Through the collective political activation efforts of the movements in such networks, this mediated mobilisation (Lievrouw, 2011) can resemble a political class movement that "enlarges participation" to the point that it has the power to "challenge the hegemony of the dominant political forces and their link with 
class interests" (Melucci, 1980, p. 204). Movement overlaps therefore demonstrate the wider implications of a political activation model for social movements' wider networks.

\section{Implications}

Where the concept of political activation was previously only applied to civic affairs, like voting and participating in the public sphere, these themes demonstrate the relevance of a political activation model to the strategies used to engender participation in class-based social movements as well. The affordances theme demonstrates the essential role ICTs play in building the capacity and mobilising capabilities of contemporary social movements, as well as the more prominent role faceto-face communications play in engendering motivation for participation. The conflict theme, on the other hand, demonstrates how movements use conflict to build the capacity and motivations of their audiences to participate, while at the same time demonstrating how capitalist logics drive mediated conflict in an attention economy. The movement overlaps theme, meanwhile, showcases how contemporary class movements are consciously focused on articulating broad motivations for participation that appeal to contiguous movements in order to pool together their activation efforts for larger, more powerful mobilisations.

Each of these themes also interacts in some way with the attention economy. Most of the affordances participants identified in the ICTs and other means of communication they used involved acquiring or retaining attention somehow, particularly on the mass scale afforded by news media. Participants' organisations also waged conflict over attention to ensure that they had enough to engage in strategies that facilitate political activation, while movement overlaps focused on pooling the attention accumulated by networked movements. These results demonstrate that attention must be treated as an additional prerequisite for participation in order to apply political activation to social movements. While the civic model for political activation may also benefit from this addition depending on the quality of the civics education of a given democracy, that model 
ultimately represents a status quo by which democracies have historically been thought to operate. In contrast, attention is quintessential for social movements because movements seek to change that status quo by their very definition; to achieve such changes, movements must first draw attention to what those changes are and why they need to happen. Figure 7 visualises this relationship by combining attention with Bode and Becker's (2018) prerequisites for political activation. Though Bode and Becker's activation model is somewhat nonlinear (p. 1574), attention's relationship to the political activation model for social movements is much more stringent as it is demonstrably required to address capacity, motivation or mobilisation at all.

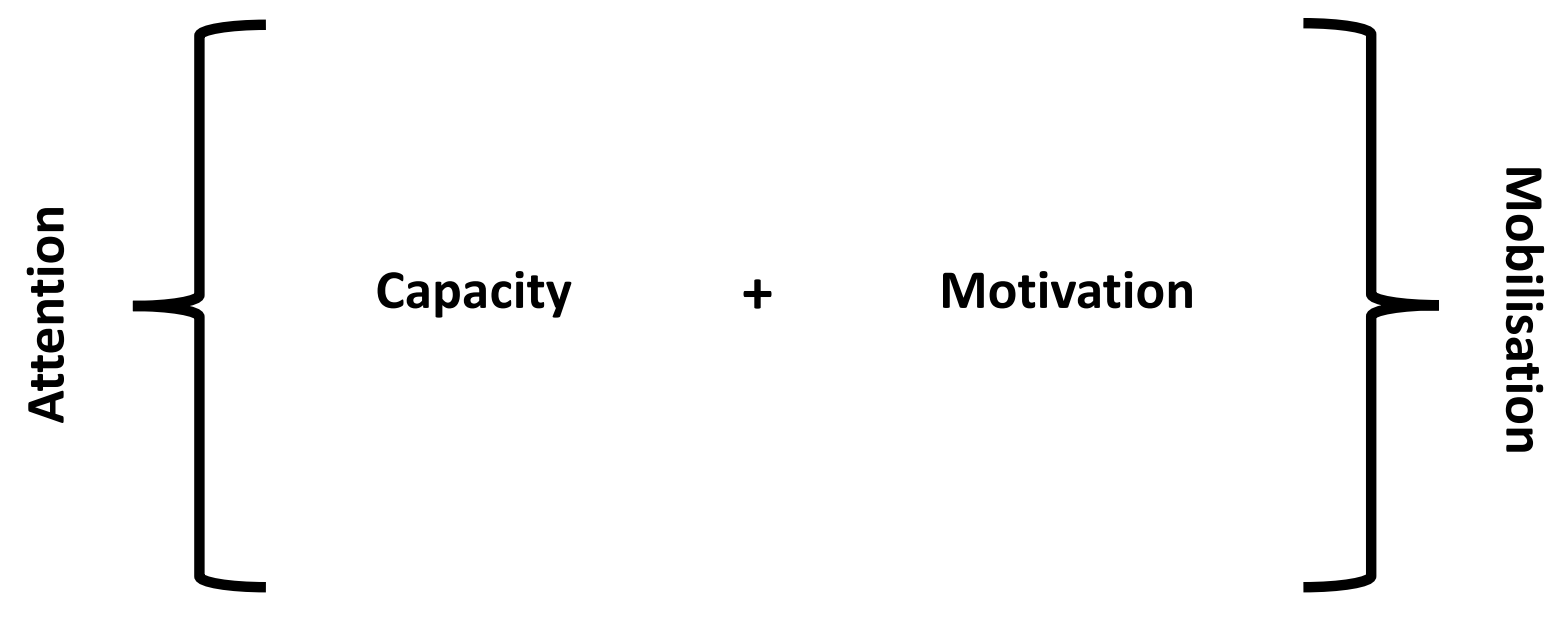

Figure 7: A diagram modelling a political activation process for social movements that is informed by the attention economy.

The application of political activation to social movements coincides with trends in social movement literature toward the legitimation of social movements within Western democracies (della Porta \& Diani, 2006,). As Xenos, Vromen and Loader argue, participation in social movements constitute a "newly emerging norm of citizenship" for young people (2014, p. 155). By expanding a concept designed originally for understanding how people come to participate in civic political affairs, these results serve to further legitimate those emerging norms. Doing so not only contributes to the literature on political activation by expanding what that literature considers "political", but can also provide tools to help organisers crystallise their understandings of how their contexts inform the strategies they develop to build their movements. 
The incorporation of attention into a political activation model for social movements also reinforces the necessity for NSM scholarship to consider the influence of capitalism on the attention economy, within which those movements operate every bit as much as class-oriented movements. This research therefore not only acknowledges, but builds on Hetland and Goodwin's call to "bring capitalism back into social movement studies" $(2013$, p. 102) by identifying media as a specific object of analysis that is equally relevant to class-oriented movements and NSMs.

Finally, this research contributes to critiques of the democratic thesis by demonstrating through the diversity of the participating organisations' media strategies that the affordances of ICTs are not distributed equally/democratically. Much as Barney (2006) expresses concerns that emerging media technologies replace collective action with communicative action (p. 89), and Dean argues that those technologies replace messages with commodified contributions (2009, p. 26), so too is the promise of equal access to the public sphere replaced by context-dependency driven by the filtering mechanisms of the attention economy. However, this research also expands on Barney and Dean's critiques by demonstrating that as much as those contexts constrain political activity, they also afford opportunities to politically activate people that are unique to those contexts. 


\section{Conclusion}

This thesis asks how social movement organisations focused on working-class issues use media to acquire the attention of their desired audiences, as well as how such strategies fit into social movements' larger efforts to facilitate the political activation of those audiences. I recruited organisers from SMOs meeting these criteria to answer these questions because their roles require them to actively grapple with the attention economy and political activation when developing strategies for enlarging participation in their movements. Drawing upon these organisers' experiences, I found that what they do to facilitate political activation through media was best understood through three themes that represent the theoretical objects around which their strategies are based: affordances, conflicts and movement overlaps. Participants' interpretations of the affordances of ICTs and other means/modes of communication primarily focused on acquiring attention and mobilising, and to a lesser extent addressed the capacity and motivation prerequisites for activation. Conflicts and movement overlaps enabled participants to fill these gaps, however; respectively, they introduced opportunities to model what participation looks like to their audiences and to articulate motivations for mobilisation that resonated across the networks connecting different movements.

Additionally, I found that each of these themes encompasses obstacles to implementing participants' media strategies that are symptomatic of an attention economy driven by capitalist logics. These obstacles demonstrate that while SMOs can use ICTs to enable political participation through their movements, those technologies are equally capable of constraining participation, thereby contradicting the thesis that technology inherently enhances democratic political processes by sheer virtue of its accessibility. To address these issues, this thesis ultimately argues for the inclusion of attention as another prerequisite of political activation when the concept is applied to social movements. 
However, the highly contextual nature of the findings in this research makes those findings difficult to generalise. In some ways, this proved useful for contributing to critiques of the democratic thesis by demonstrating that ICTs do not afford equal access to democracy. However, the contextual nature of the findings also highlights the limitations endemic to qualitative research, as well as to the small size of the sample I produced. As described previously, in order to determine how class-based social movements use media, I had to 1) identify class-based SMOs that I could access, and 2) find people within those organisations who had knowledge of or experience with those organisations' media practices. Few organisations met the first criteria, but each had more than one potential interviewee who met the second criteria for participation. The constraints on the sample size could therefore have been ameliorated by expanding the sample to include more than one participant per organisation, though this sampling method would require an equal number of interviewees per participating organisation to prevent bias.

Bias became more of a concern when, in order to increase the sample size, I decided to include an SMO I was already part of (PAPA) in the research. While conducting this research, I became conscious of how my longer experience with PAPA compared to the other participating organisations could bias the research toward my own understanding of how PAPA operates. Though I made efforts to bracket those experiences by balancing them out with participation in the other organisations in the sample, as described in the methodology chapter, the possibility remains that my longer history with PAPA informs the analysis in some way.

To address the sampling issues faced by this research, future studies might shift the scope from movement type (i.e. class-based movements in the case of this thesis) to the role of specific strategies used by social movements to facilitate political activation. AAAP's media spokesperson training, for example, closely resembles Funke et al.'s (2018) case study given how both facilitate the production of media with the base of their given movement bases. UW and PAPA did not describe any easily identifiable equivalents, but reorienting the scope of future research around this strategy 
could enable an exploration of how the co-production of media addresses the prerequisites of political activation.

I could also have further explored the nature of the conflicts waged by SMOs and their oppositional actors. Though one of the themes of the analysis centred on these conflicts, incorporating the work of Stuart Hall in this area would enable a deeper analysis of social movement media. Hall's work framing social fields as power relations between actors (1988) presents an opportunity to better understand the nature of the attention economy and its role in the accumulation of social and culture capital on an organisational level.

Scoping constraints notwithstanding, this research still demonstrates the value of a political activation model to strategies for building social movements. By applying this model to participants' media strategies, it is possible to identify how the outcomes of political activation may be linked to the way SMOs use the tools at their disposal, how those outcomes are informed by the nature of movements' conflicts, and the nature of those movements' relationships to other movements to meet the various activation prerequisites (i.e., capacity, motivation and mobilisation) of their desired audiences. Through this process, I conclude that acquiring attention constitutes another such activation prerequisite of social movements, for which capturing that attention is much less of a guarantee. With this foundation established, further research might therefore explore the role of attention in the political activation processes of social movements in greater depth, especially given the extra hurdles social movements must clear in order to draw attention to alternatives to the status quo.

Though the attention economy and the information and communication technologies enabling that economy can significantly constrain the activities of social movements, Dean argues that those technologies nevertheless afford us the ability to "experience the force of many" through regular exposure to the masses that reassure people they "are not unique but common" (2016, p. 65). This thesis demonstrates that access to that commonality and the potential it has to politically 
activate the masses is not guaranteed by those technologies alone, but neither is it wholly foreclosed by them. Rejecting both positive and negative fetishisation of media's ability to facilitate democracy in this way is of paramount importance to the political left; doing so establishes a clearer pathway toward the mass mobilisation of the proletariat, one of the most fundamental requirements for the dissolution of capitalism. 


\section{References}

Arendt, H. (2013). The human condition. University of Chicago Press.

Auckland Action Against Poverty. (n.d.). About Us. Auckland Action Against Poverty. Retrieved from https://www.aaap.org.nz/about

Auckland Action Against Poverty. (2017). AAAP says stop the war on the poor (\#notenoughleft). Retrieved from https://d3n8a8pro7vhmx.cloudfront.net/aaap/pages/128/attachments/original/150422984 2/Not_Enough_Left_demand_document.pdf?1504229842

Auckland Action Against Poverty. (2019a, January 17). We're starting the year by calling for a substantial increase in baseline benefit levels [Facebook post]. Retrieved from https://www.facebook.com/AAAPNZ/posts/2908265202520737?_tn_=-R

Auckland Action Against Poverty. (2019b, May 3). Government ignores most of welfare report recommendations. Scoop. Retrieved from http://www.scoop.co.nz/stories/PO1905/S00050/government-ignores-most-of-welfarereport-recommendations.htm

Auckland Action Against Poverty. (2019c, July 9). We should not have to do MSD's job for them. The Spinoff. Retrieved from https://thespinoff.co.nz/society/09-07-2019/we-should-not-have-todo-msds-job-for-them/

Auckland Peace Action. (2017, February 11). We support No Pride in Prisons [Blog post]. Retrieved from https://aucklandpeaceaction.wordpress.com/2017/02/11/we-support-no-pride-inprisons

Auckland Peace Action. (2018, October 15). Action against NZDF crimes \& toxic culture tomorrow. Scoop. Retrieved from http://www.scoop.co.nz/stories/P01810/S00207/action-against-nzdfcrimes-toxic-culture-tomorrow.htm

Barney, D. (2008). Politics and emerging media: The revenge of publicity. Global media journal, 1 (Inaugural Issue), 89.

Benford, R. D., \& Snow, D. A. (2000). Framing processes and social movements: An overview and assessment. Annual review of sociology, 26(1), 611-639.

Bennett, W. L., \& Segerberg, A. (2012a). Digital media and the personalization of collective action: social technology and the organization of protests against the global economic crisis: W. Lance Bennett and Alexandra Segerberg. In Social media and democracy (pp. 23-48). Routledge.

Bennett, W. L., \& Segerberg, A. (2012b). The logic of connective action: Digital media and the personalization of contentious politics. Information, communication \& society, 15(5), 739768.

Blackledge, P. (2013). Thinking About (New) Social Movements: Some Insights from the British Marxist Historians. In Marxism and social movements (pp. 257-275). Brill.

Blake-Persen, N. (2019, July 4). People queue from 2am outside Work and Income for help. Checkpoint. Retrieved from 
https://www.rnz.co.nz/national/programmes/checkpoint/audio/2018702678/peoplequeue-from-2am-outside-work-and-income-for-help

Bode, L., \& Becker, A. B. (2018). Go Fix It: Comedy as an Agent of Political Activation. Social Science Quarterly, 99(5), 1572-1584.

Boulianne, S. (2015). Social media use and participation: A meta-analysis of current research. Information, communication \& society, 18(5), 524-538.

Braun, V., \& Clarke, V. (2013). Successful qualitative research: A practical guide for beginners. sage.

Bruns, A. (2019). Are Filter Bubbles Real?. John Wiley \& Sons.

Bucher, T., \& Helmond, A. (2018). The affordances of social media platforms. The SAGE handbook of social media, 233-253.

Burgmann, V. (2016). Globalization and Labour in the Twenty-first Century (p. 261). Abingdon, United Kingdom: Routledge.

Burrow, A. (2015, December 15). Campaigners slam lack of action on child poverty. Newstalk ZB. Retrieved from https://www.newstalkzb.co.nz/news/national/campaigners-slam-lack-ofaction-on-child-poverty

Cammaerts, B., Mattoni, A., \& McCurdy, P. (Eds.). (2013). Mediation and protest movements. Intellect Books.

Castells, M. (2007). Communication, power and counter-power in the network society. International journal of communication, 1(1), 29.

Castells, M. (2012). Changing the world in the network society. Networks of outrage and hope, 246271.

Charles Royal, T. A. (n.d.). Story: Papatūānuku - the land. Te Ara - The encyclopedia of New Zealand. Retrieved from https://teara.govt.nz/en/papatuanuku-the-land

Harsh punishments for sole parents fuel child poverty. (2017, September 15). Child Poverty Action Group. Retrieved from https://www.cpag.org.nz/news/harsh-punishments-for-sole-parentsfuel-child/

Christensen, H. S. (2011). Political activities on the Internet: Slacktivism or political participation by other means?. First Monday, 16(2).

Christensen, H. S., \& Bengtsson, Å. (2011). The political competence of Internet participants: Evidence from Finland. Information, communication \& society, 14(6), 896-916.

The Civics and Media Project. (2016). Proceedings of the civics and media project: a report on the three workshops held in 2015. McGuiness Institute.

No Pride in Prisons on abolitionist politics. (2017). Counterfutures: left thought \& practice Aotearoa, Issue 3, 129-147. Rebel Press.

D'Cruz, C. (2014). Commemorating Homosexual: Rethinking experience and the disaffected through the legacies of the Gay Liberation Movement. Sexualities, 17(3), 291-309. 
Daley, M. (2019, July 6). Auckland Action Against Poverty hits back at Government over WINZ queues. Stuff. Retrieved from https://www.stuff.co.nz/national/114046076/carmelsepuloni-to-meet-community-groups-amid-work-and-income-queue-claims

Daley, M., \& MacManus, J. (2019, July 5). Minister responds to Manurewa Work \& Income queue problem. Stuff. Retrieved from https://www.stuff.co.nz/national/114022059/ministerresponds-to-manurewa-work--income-queue-problem?rm=m

Davenport, T. H., \& Beck, J. C. (2001). The attention economy: Understanding the new currency of business. Harvard Business Press.

Dean, J. (2009). Democracy and other neoliberal fantasies: Communicative capitalism and left politics. Duke University Press.

Dean, J. (2014). Communicative capitalism and class struggle. Spheres: Journal for digital cultures, 1 , 1-16.

Dean, J. (2016a). Crowds and party. Verso Books.

Dean, J. (2016b, November 26). Not Us, Me. Verso. Retrieved from https://www.versobooks.com/blogs/2970-not-us-me

Della Porta, D., \& Diani, M. (2009). Social movements: An introduction. John Wiley \& Sons.

2018 Edelman Trust Barometer. (2018) Edelman.

Featherstone, M. (2009). Ubiquitous media: an introduction. Theory, culture \& society, 26(2-3), 1-22.

Fiorina, M. P. (2002). Parties, participation, and representation in America: Old theories face new realities. Political science: The state of the discipline, 511-541.

Flahive, B. (2019, May 3). Government to scrap benefit sanctions for solo mums, among welfare changes. Stuff. Retrieved from https://www.stuff.co.nz/national/politics/112435767/government-to-scrap-benefitsanction-for-solo-mums-employ-263-frontline-staff-to-help-beneficiaries-find-work

Gill, R. (2016). Post-postfeminism?: New feminist visibilities in postfeminist times. Feminist media studies, 16(4), 610-630.

Groot, S., Van Ommen, C., Masters-Awatere, B., \& Tassell-Matamua, N. (Eds.). (2017). Precarity: Uncertain, insecure and unequal lives in Aotearoa New Zealand. Massey University Press.

Hall, S. (1988). The hard road to renewal: Thatcherism and the crisis of the left. Verso.

Harbridge, R., \& Hince, K. (1993). Unions and Union Membership in New Zealand 1985-1992. New Zealand journal of industrial relations, 18(3).

Harcup, T., \& O'neill, D. (2017). What is news? News values revisited (again). Journalism studies, 18(12), 1470-1488.

Hardoon, D., Fuentes-Nieva, R., \& Ayele, S. (2016). An economy for the 1\%: How privilege and power in the economy drive extreme inequality and how this can be stopped. Oxfam International.

Harris, S. (2017, July 6). Sanction hurting solo mums by reducing benefit for not naming father. NZ Herald. Retrieved from https://www.nzherald.co.nz/nz/news/article.cfm?c_id=1\&objectid=11886812 
Hayek, F. A. (2014). The road to serfdom: Text and documents: The definitive edition. Routledge. (Original work published in 1944).

Hetland, G., \& Goodwin, J. (2013). 3. The Strange Disappearance of Capitalism from Social Movement Studies. In Marxism and social movements (pp. 82-102). Brill.

Hutchby, I. (2014). Communicative affordances and participation frameworks in mediated interaction. Journal of pragmatics, 72, 86-89.

Inglehart, R. (1981). Post-materialism in an environment of insecurity. American political science review, 75(4), 880-900.

Johl, S. K., \& Renganathan, S. (2010). Strategies for gaining access in doing fieldwork: Reflection of two researchers. Electronic journal of business research methods, 8(1), 42.

Kennedy, M. (2016). The Māori Renaissance from 1972. A history of New Zealand literature. Cambridge University Press.

Koopmans, R. (2004). Movements and media: Selection processes and evolutionary dynamics in the public sphere. Theory and society, 33(3-4), 367-391.

Lamusse, T. (2018). Strategies for Building the Revolutionary Left. Counterfutures: left thought \& practice Aotearoa, Issue 6, 121-138. Rebel Press.

Lamusse, T, Morgan, S, \& Rākete, E. (Eds.). (2016). Abolitionist demands: toward the end of prisons in Aotearoa. No Pride in Prisons Press.

Lane, D. S., Kim, D. H., Lee, S. S., Weeks, B. E., \& Kwak, N. (2017). From online disagreement to offline action: How diverse motivations for using social media can increase political information sharing and catalyze offline political participation. Social media+ society, 3(3), 2056305117716274.

Lang, S. K. W. (2011). Bicultural responsiveness in Aotearoa New Zealand: an immigrant counsellor's perspective: a thesis presented in partial fulfilment of the requirements for the degree of Doctor of Philosophy in Education, Te Kupenga o te Mātauranga, Aotearoa New Zealand (Doctoral dissertation, Massey University).

Lewis, A. J. (2016). "We Are Certain of Our Own Insanity": Antipsychiatry and the Gay Liberation Movement, 1968-1980. Journal of the history of sexuality, 25(1), 83-113.

Lievrouw, L. (2011). Alternative and activist new media. Polity.

Loader, B. D., Vromen, A., \& Xenos, M. A. (2014). Introduction: The networked young citizen: Social media, political participation and civic engagement. In The networked young citizen (pp. 1730). Routledge.

Locke, E. (1992). Peace people: a history of peace activities in New Zealand. Hazard Press.

Luders, J. E. (2010). The civil rights movement and the logic of social change. Cambridge University Press.

Marae. (2019, July 31). \#WATCH Minister Carmel Sepuloni was on with Miriama Kamo after footage of people lining up for hours in the cold outside of the WINZ office in Manurewa [Facebook post]. Retrieved from 
https://www.facebook.com/maraetv/posts/2275023439242765?comment_id=2276118655 799910

Marx, K. (2013). Capital. Verso. (Original work published in 1867).

Marx, K., \& Engels, F. (2016). Manifesto of the communist party: A modern edition. Verso. (Original work published in 1848).

Marx, K. (2009). A contribution to the critique of political economy. Marxists Internet Archive. (Original work published in 1859). Retrieved from https://www.marxists.org/archive/marx/works/1859/critique-pol-economy

McAdam, D. (1999). Political Process and the Development of Black Insurgency, 1930-1970, 2. Aufl., Chicago, IL.

McAlevey, J. (2018). No shortcuts: organizing for power in the new gilded age. Oxford University Press.

McDevitt, M., \& Chaffee, S. H. (2002). The family in a sequence of political activation: why civic interventions can succeed. Journalism \& communication monographs, 4(1), 6-42.

Mead, H. M. (2016). Tikanga Maori (revised edition): Living by Maori values. Huia publishers.

Melucci, A. (1980). The new social movements: A theoretical approach. Information (International Social Science Council), 19(2), 199-226.

Melucci, A. (1994). A strange kind of newness: What's 'new' in new social movements?. New social movements: From ideology to identity, 101-130.

Newman, A., \& Jess, C. (2015). Renewing New Zealand Unions: The Service And Food Workers' Union \& Living Wage Aotearoa. Labour, employment and work in New Zealand.

Newstalk ZB staff. (2019, May 3). The Government's latest changes to the welfare system. Newstalk $Z B$. Retrieved from https://www.newstalkzb.co.nz/on-air/heather-du-plessis-allandrive/audio/the-governments-latest-changes-to-the-welfare-system

Nissen, S. (2019). Student political action in New Zealand. Bridget Williams Books.

No Pride in Prisons. (2015, February 22). Transgender woman's arm broken by police at pride parade. Scoop. Retrieved from http://www.scoop.co.nz/stories/AK1502/S00523/transgender-womans-arm-broken-bypolice-at-pride-parade.htm

No Pride in Prisons. (2017, August 5). No Pride in Prisons name change upcoming. Scoop. Retrieved from http://www.scoop.co.nz/stories/PO1708/S00109/no-pride-in-prisons-name-changeupcoming.htm

O'Carroll, A. D. (2013). Kanohi ki te kanohi-a thing of the past? An examination of Māori use of social networking sites and the implications for Māori culture and society: a thesis submitted for the Degree of Doctor of Philosophy at Massey University (Doctoral dissertation, Massey University).

Offe, C. (1985). New social movements: challenging the boundaries of institutional politics. Social research, 52(4), 817. 
Oil Free Wellington. (2018a, October 19). Oil Free Wellington supports bus strike action. Scoop. Retrieved from http://www.scoop.co.nz/stories/PO1810/S00293/oil-free-wellingtonsupports-bus-strike-action.htm

Oil Free Wellington (2018b, October 20). We're supporting the strike action and the rally on Monday, Cuba st $12 \mathrm{pm}$, because bus drivers deserve decent pay and working conditions. Climate Justice Now! [Facebook post]. Retrieved from https://www.facebook.com/OilFreeWellington/posts/1927815970633724?_tn__=-R

Osanloo, A., \& Grant, C. (2016). Understanding, selecting, and integrating a theoretical framework in dissertation research: Creating the blueprint for your "house". Administrative issues journal: connecting education, practice, and research, 4(2), 7.

Pariser, E. (2011). The filter bubble: What the internet is hiding from you. Penguin UK.

People Against Prisons Aotearoa. (n.d.). Our Kaupapa. People Against Prisons Aotearoa. Retrieved from https://papa.org.nz/our-kaupapa

People Against Prisons Aotearoa. (2017, September 1). No Pride in Prisons is now People Against Prisons Aotearoa. Scoop. Retrieved from http://www.scoop.co.nz/stories/P01709/S00010/no-pride-in-prisons-is-now-peopleagainst-prisons-aotearoa.htm

People Against Prisons Aotearoa. (2018, October 31). People Against Prisons Aotearoa to oppose weapons expo. Scoop. Retrieved from http://www.scoop.co.nz/stories/PO1810/S00421/people-against-prisons-aotearoa-tooppose-weapons-expo.htm

Peterson, R. D. (2010). Putting voters in context: social and cognitive activation in political campaigns. University of California, Davis.

Pichardo, N. A. (1997). New social movements: A critical review. Annual review of sociology, 23(1), 411-430.

Prior, M. (2010). You've either got it or you don't? The stability of political interest over the life cycle. The journal of politics, 72(3), 747-766.

Reiman, J., \& Leighton, P. (2015). Rich get richer and the poor get prison, the (subscription): Ideology, class, and criminal justice. Routledge.

Ryall, S., \& Blumenfeld, S. (2016). Unions and Union Membership in New Zealand: report on 2015 Survey. Centre for Labour, Employment and Work (CLEW), Wellington, Victoria University of Wellington.

Satherley, D. (2019, May 14). Prison does almost nothing to stop violent crime - study. Newshub. Retrieved from https://www.newshub.co.nz/home/world/2019/05/prison-does-almostnothing-to-stop-violent-crime-study.html

Sawchuk, P. H. (2011). Anti-Poverty Activism from a CHAT Perspective: A Comparison of Learning across Three Organizations. Adult Education Research Conference 2011 Proceedings, 611617. New Prairie Press.

Sørensen, M. J. (2016). Humour in political activism: Creative nonviolent resistance. Springer. 
Srnicek, N. (2017). The challenges of platform capitalism: Understanding the logic of a new business model. Juncture, 23(4), 254-257.

Standing, G. (2014). The Precariat-The new dangerous class. Amalgam, 6(6-7), 115-119.

Steven. (2007, February 26). "Records of the strike in Egypt under Ramses III, c1155BC." Libcom.org. Retrieved from https://libcom.org/history/records-of-the-strike-in-egypt-under-ramsesiii?fbclid=IwAROWktHnXubJcl1ZIlekAIIL6yQRGqDhbb_Gn_mfjCAfB10X2keubOrCwtA

Taonui, R. (2017). Ngā tuakiri hōu - new Māori identities - Māori renaissance. Te Ara - The Encyclopedia of New Zealand. Retrieved from https://teara.govt.nz/en/nga-tuakiri-hou-newmaori-identities/page-3

Taylor, D., \& Grey, S. (2014). From class-struggle to neoliberal narratives: Redistributive movements in Aotearoa/New Zealand. New Zealand Sociology, 29(3), 69.

Tsatsou, P. (2018). Social Media and Informal Organisation of Citizen Activism: Lessons From the Use of Facebook in the Sunflower Movement. Social media + society, 4(1), 2056305117751384.

Tufford, L., \& Newman, P. (2010). Bracketing in qualitative research. Qualitative social work, 11(1), 80-96.

Unions Wellington. (2018, October 19). Oil Free Wellington spokesperson James Barber says, "we believe in climate justice. Climate change needs to be tackled in a fair and equitable way which makes the world better for the marginalized. This includes supporting workers in their struggle for fair working conditions [Facebook post]. Retrieved from https://www.facebook.com/UnionsWellington/posts/1155256374622475?_tn_=-R

Wellington trains grind to halt as rail workers strike. (2017, November 16). Stuff. Retrieved from https://www.stuff.co.nz/dominion-post/news/98893397/wellington-rail-workers-to-strikeon-thursday

Wellington trains to run on Friday after union calls off strike action. (2017, November 30). Stuff. Retrieved from https://www.stuff.co.nz/national/99417390/wellington-train-strike-calledoff

West, D. (2004). New social movements. Handbook of political theory, 265-276.

Williams, J. (2018). Stand out of our light: Freedom and resistance in the attention economy. Cambridge University Press.

Winter, C. (2018a, February 1). Owners of Wellington's Five Boroughs take out personal loan to pay staff. Stuff. Retrieved from https://www.stuff.co.nz/business/101070634/five-boroughsstaff-to-get-holiday-pay-by-thursday-afternoon

Winter, C. (2018b, January 30). Union says Five Boroughs staff had little notice about closure, leaves many out of pocket. Stuff. Retrieved from https://www.stuff.co.nz/business/industries/100990890/five-boroughs-restaurant-put-intovoluntary-liquidation-owing-more-than-440k?rm=m.

Xenos, M. A., Vromen, A., \& Loader, B. D. (2014). The great equalizer? Patterns of social media use and youth political engagement in three advanced democracies. In The networked young citizen (pp. 33-54). Routledge.

Zhang, A. M. (2002). The origins of the African-American Civil Rights Movement. Routledge. 


\section{Glossary}

Acronyms, in order of appearance:

NSM - New Social Movement

SMO - social movement organisation

ICT - information and communications technology

PAPA - People Against Prisons Aotearoa

NPIP - No Pride in Prisons

UW - Unions Wellington

NZCTU - New Zealand Council of Trade Unions

AAAP - Auckland Action Against Poverty

PSA - Public Service Association

OFW - Oil Free Wellington

PAW - Peace Action Wellington

PAH - Peace Action Hamilton

APA - Auckland Peace Action

PAM - Peace Action Manawatu

NZDIA - New Zealand Defence Industry Association

CPAG - Child Poverty Action Group

Ngā kupu o te reo Māori, in order of appearance:

Tāmaki Makaurau - Auckland

Tikanga [Māori] - correct procedure, practice, protocol [as determined by Māori]

Taonga - treasure, anything prized (or valued)

Te reo Māori - Māori language

Te ao Māori - the Māori world

Pākehā - white European settler

Whakapapa - genealogy, ancestry

Kanohi ki te kanohi - face to face, in person

Whānau - family

Kaupapa - purpose/programme/theme 
Kanohi kitea - to have a physical presence, be seen

Te Whanganui-ā-tara - Wellington

Mana motuhake - Māori self-determination

Whāngai - foster, adopt

Tangi - funeral

He tangata, he tangata, he tangata - of the people, for the people, by the people

Whakaaro - thoughts, perspectives, opinions

Whakawhanaungatanga - the process of establishing relationships 


\section{Appendix: Interview schedule}

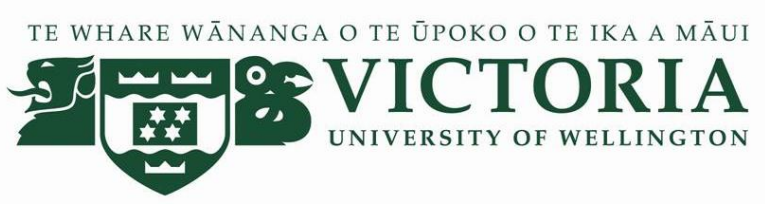

\section{Interview schedule}

What organisation are you representing today?

- What are your organisation's goals/values/kaupapa?

- How does your kaupapa tackle working-class issues? How would you define those issues?

- How is your organisation structured/governed?

- What is your role within this organisation/how do you contribute?

- How did you get involved? Can you think of any examples of media that might have played a role?

How do you get other people to care about your issues and goals?

- How important do you think online media to getting people invested?

- How does this compare/relate to kanohi ki te kanohi (face-to-face) interaction or other mediums that your organisation uses?

- What are the main obstacles/counterpoints that you deal with when engaging with people and getting them invested?

- What sort of rhetoric do you generally find the most effective?

How have you established who your organisation's audience is?

- Which groups do you spend the most resources reaching out to?

- What do you think makes this audience likely to respond to your messaging?

- What do you want this response to be?

- How do you connect personally to the communities/groups/people that you reach out to (socially, emotionally, experientially)?

How does your organisation use media to encourage participation?

- How do you use various news/social media platforms to reach and/or galvanise your audience?

- Do social media create more connections with potential recruits than the news?

- How do you write/produce your content? What do you take into consideration when doing so?

- How often do you write press releases/posts for this/these platform(s)? What difference does this make?

What do you think is the most important factor in getting your audiences from "interested" to "actively participating"?

- (Review previously discussed information produced)

- How do you involve the people you advocate for?

- What general pathways to involvement does your organisation have?

Is there anything else that you think is essential to how digital media are used to build or maintain movements? 